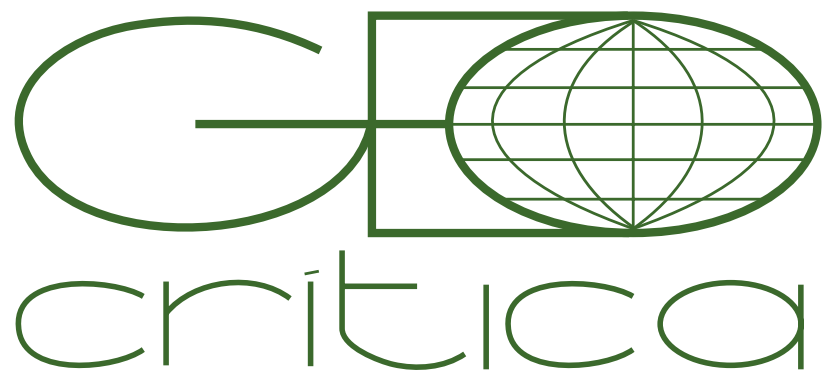

\section{Scripta Nova}

Revista Electrónica de Geografía y Ciencias Sociales Universitat de Barcelona

1 de julio de 2017

\title{
A CRIAÇÃO DE GEOETNOGRAFIAS COMO METODOLOGIA PARA O ESTUDO DOS RITMOS URBANOS. UMA APLICAÇÃO NO CHIADO, LISBOA
}

\author{
Daniel Paiva \\ Herculano Cachinho \\ Teresa Barata-Salgueiro \\ Anselmo Amílcar \\ Centro de Estudos Geográficos, Universidade de Lisboa \\ daniel.paiva@campus.ul.pt
}

Recibido: 5/12/2016; Devuelto para revisión: 5/03/2017; Aceptado: 23/03/2017

Este artigo tem por base investigação desenvolvida no âmbito do projeto CHRONOTOPE -

Time-space Planning for Resilience Cities (URBAN/002/2009), financiado pela Fundação para a Ciência e a Tecnologia e parte da rede de investigação Urban-Net, e do projeto de doutoramento "Som urbano: territórios, atmosferas afetivas e políticas" (SFRH/ BD/108907/2015), financiado pela Fundação para a Ciência e a Tecnologia.

\section{A criação de geoetnografias como metodologia para o estudo dos rit- mos urbanos. Uma aplicação no Chiado, Lisboa (Resumo)}

A literatura atual sobre ritmos urbanos divide-se entre abordagens que procuram quantificar e determinar padrões rítmicos em espaços urbanos e perspetivas qualitativas que procuram qualificar a fluidez rítmica da cidade e observar a ecologia dos ritmos humanos, sociais e urbanos. De modo a aproximar estas duas perspetivas, apresentamos o uso de geoetnografias como meio de combinar uma visão de cima com uma visão a partir do terreno que permite analisar os padrões espácio-temporais sem os reduzir a um estado de stasis. A partir de um estudo realizado entre 2012 e 2016 na área do Chiado, em Lisboa, mostramos como a criação de uma geoetnografia nos permitiu compreender os ritmos urbanos no Chiado em profundidade.

Palavras-chave: Geoetnografia, ritmos urbanos, geografia cultural, espaço público

\section{The creation of geoethnographies as a research methodology for urban} rhythms. An application on Chiado, Lisbon (Abstract)

Literature on urban rhythms is currently divided between approaches that seek to quantify and determine rhythmic patterns in urban spaces and qualitative perspectives which seek to qualify the rhythmic flows of the city and observe the ecology of human, social and urban rhythms. In order to approach these two perspectives, we present the use of geoethnographies as a means to combine an aerial vision with a terrain vision that allows analyzing spacetime patterns without reducing them to a state of stasis. Based on a study conducted between 2012 and 2016 in Chiado, Lisbon, we show that the creation of a geoethnography allowed us to understand Chiado's rhythms in depth.

Key words: Geoethnography, urban rhythms, cultural geography, public space 
Desde o início do século XXI, tem-se assistido na geografia urbana a uma renovação do interesse por métodos etnográficos ancorados na observação direta e participante, na sequência de uma necessidade de abordar as dinâmicas vividas do espaço, motivada por novas perspectivas teóricas como a ritmanálise, as teorias não-representacionais ou a teoria ator-rede. Estas perspectivas têm em comum a intenção de abordar o espaço urbano não como um objecto estático e concreto, mas como uma dinâmica partilhada e em movimento: um espaço-movimentol ou um espaço-tempo2. Neste contexto, a observação direta tem sido considerada uma ferramenta fundamental para abordar o espaço urbano enquanto composição rítmica3, mas também tem sido identificada uma necessidade de repensar este método. A geografia tem uma longa história de criação de etnografias através de observação direta e observação participante4, mas a intensidade desta produção tem sido intermitente. Após um uso intensivo de métodos etnográficos durante a vigência do paradigma da geografia regional de influência vidaliana, verificou-se um declínio após o estabelecimento das geografias quantitativas na década de 1960. Durante a década de 1970, com a emergência das geografias críticas5, e já neste século, com a proliferação de estudos de índole pós-estruturalista, essas metodologias foram recuperadas, mas também repensadas6. Neste período mais recente, o interesse em métodos etnográficos está ligado à necessidade de estudar as questões performativas da vida urbana, com especial enfoque no afeto, no movimento, na temporalidade, nas práticas, nos hábitos, nas sensações, e em processos não-representacionais7. Nesse sentido, têm sido realizadas várias experimentações metodológicas com o intuito de aproximar o geógrafo da experiência sensível dos fenómenos que estuda, como o uso de diários8 ou o recurso a novas tecnologias9. Pretende-se com isto que o geógrafo mergulhe no terreno, participe na ação social, e esteja sujeito às afetações e sensações do dia a dia urbano, de modo a permitir que o conhecimento geográfico possa usufruir da subjetividade empírica, criando relatos do terreno que aprofundem questões à escala local ou individual, explicando dinâmicas espaciais e sociais de um modo participadolo.

Neste artigo, pretendemos contribuir para este corpo crescente de literatura ao abordar um problema central que se coloca à metodologia do estudo das dinâmicas da vida urbana: como abordar a vida urbana enquanto conjunto de padrões espácio-temporais, sem deixar de parte as intervenções e emergências temporárias que rompem com esses padrões?

\footnotetext{
1 Thrift, 2008.

2 Massey, 2005; Crang, 2012.

3 Em estudos como Simpson, 2008; Vergunst, 2010; Wunderlich, 2013; Aalbrecht, 2016.

4 Velasco-Graciet, 2008.

5 Peet, 1998.

6 Cresswell, 2012.

7 Thrift e Dewsbury, 2000; Anderson, 2009; Thrift, 2011; Ash e Simpson, 2014.

8 Latham, 2003; Duffy e Waitt; 2011; Paiva, 2016.

9 Simpson, 2012; Gallagher e Prior, 2014; Spinney, 2015.

10 McCormack, 2013; Vannini, 2015a; Vannini, 2015b.
} 
Tendo por base a investigação sobre os ritmos do Chiado, no centro de Lisboa, realizada no projeto CHRONOTOPE - Time-space Planning for Resilience Cities (URBAN/002/2009)11 e no projeto "Som urbano: territórios, atmosferas afetivas e políticas" ( SFRH/BD/108907/2015), iremos aqui apresentar o uso de geoetnografias no estudo de ritmos urbanos como meio de combinar uma visão de cima com uma visão a partir do terreno que permite analisar os padrões espácio-temporais do Chiado sem os reduzir a um estado de stasis. Defendemos que a criação de geoetnografias dos ritmos urbanos - nomeadamente a complementaridade entre a vista aérea e a perspetiva a partir do terreno - permite evitar tanto a falácia do 'truque de deus'12 em que a geografia 'top-down' por vezes cai, como o particularismo e indeterminação que por vezes limita os estudos urbanos à escala micro ${ }^{13}$.

O artigo dividir-se-á em cinco secções. Iremos começar com uma curta discussão sobre as novas perspetivas sobre espaço urbano e os estudos sobre ritmos urbanos. Com isso em mente, iremos de seguida abordar o potencial da da geoetnografia enquanto ferramenta para captar os ritmos do espaço urbano contemporâneo. De seguida, apresentaremos o local do estudo. Depois, iremos descrever a metodologia do nosso estudo em dois momentos: um dedicado à construção de uma perspetiva sobre os ritmos urbanos 'a partir da janela', que teve o propósito de identificar os padrões de apropriação do espaço urbano no Chiado; e outra relativamente à construção de uma perspetiva a partir do terreno, destinada a compreender o impacto das emergências temporárias e fenómenos afetivos e sensoriais nos ritmos urbanos. Finalmente, faremos uma pequena discussão sobre as possibilidades oferecidas por esta metodologia.

\section{Espaço, Tempo, Relações, Movimento, Ritmo}

A geografia tem adoptado diferentes perspetivas sobre o espaço ao longo da história da disciplina. Na última década, tem-se tornado consensual que o conceito de espaço deve ser expandido se queremos abordar a plenitude da sua agência. Neste sentido, podem-se encontrar três argumentos que se complementam.

Em primeiro lugar, posiciona-se o argumento a favor de considerar o espaço e o tempo como elementos inseparáveis ${ }^{14}$. As palavras de Massey providenciam um excelente ponto de partida nesta matéria:

E se (...) abandonarmos a assunção que o espaço e o tempo são opostos mutuamente exclusivos? E se o espaço não é a esfera de uma multiplicidade discreta de coisas inertes, ainda que interrelacionadas na sua totalidade? Desse modo, o espaço não será um conjunto já interconectado, mas um produto contínuo de interconexões e de ausência de interconexões. Assim, será sempre inacabado e aberto. Esta arena de espaço não é terreno firme para nos apoiarmos. Não é de modo algum uma superfície ${ }^{15}$.

11 Adiante referido apenas como CHRONOTOPE.

12 Haraway, 1988.

13 Storper e Scott, 2016.

14 Crang, 2012.

15 Massey, 2005, p. 107. 
A vantagem de pensar em termos de espaço-tempo é que permite-nos considerar a vida dos lugares. Combinando extensão com duração, é possível pensar sobre intensidades ${ }^{16}$ porque se passa da criação de 'geografias mortas' que consistem em representações imóveis ${ }^{17}$ para a compreensão de que o espaço é um "produto contínuo de interconexões"18, levando-nos a pensar de forma diferente sobre os lugares. Estudos baseados nesta perspetiva têm posto em evidência como os lugares não são identidades pré-estabelecidas, e podem ser vistos como formações temporais ou eventos, produtos da confluência interativa de pessoas, animais, flora, tecnologias, materialidades e forças geológicas ${ }^{19}$. A conceptualização do espaço-tempo, no entanto, tem sido frequentemente caótica ${ }^{20}$, porque o espaço e o tempo interagem em miríades de modos diferentes. Não é possível, ou pelo menos é limitador, isolar espaços e tempos ou espacialidades e temporalidades singulares porque estas estão sempre ligadas a outra coisa qualquer.

Por este motivo, emerge um segundo argumento a favor de considerar o espaço como uma ecologia de relações ${ }^{21}$. Os argumentos a favor da natureza relacional do espaço-tempo emergem na sequência de diversas perspectivas teóricas que procuram descentrar a agência social do sujeito, ou das instituições. O trabalho de Latour ${ }^{22}$ e o desenvolvimento da teoria ator-rede é central neste ponto. Latour ${ }^{23}$ argumenta que devemos "seguir os próprios atores" e, ao mesmo tempo, aumentar o espectro daquilo que podemos considerar como atores, para incluir objetos, materialidades, animais, entre outros. Estes seriam considerados actantes, para os distinguir dos atores humanos. Deste modo, as ciências sociais podem descrever como as associações de diversos atores e actantes se tornam em agência coletiva. O enfoque no conceito de afeto (que se refere às capacidades de afetar e ser afetado) na filosofia pós-estrutural $^{24}$ e na pós-fenomenologia ${ }^{25}$, e a sua influência nas ciências sociais através daquilo que ficou conhecido como a 'viragem afetiva' ${ }^{26}$, também contribuiu para um maior foco nas relações entre atores, abordando-se aspetos não-representacionais antes descurados como o hábito ${ }^{27}$, o half-second delay ${ }^{28}$ ou as atmosferas ${ }^{29}$.

Na sequência da perspetiva do espaço enquanto um contínuo temporal e relacional, surge um outro argumento a favor do espaço enquanto movimento. Esta perspetiva está ligada ao desenvolvimento das tecnologias de transporte e a per-

16 McCormack, 2013.

17 Thrift e Dewsbury, 2000.

18 Massey, 2005: 107

19 Massey, 2005; Amin, 2008.

20 Crang, 2012.

21 Simpson, 2008.

22 Latour, 2005.

23 Latour, 2005, p. 12.

24 Deleuze, 1988; Deleuze e Guattari, 1987.

25 Henry, 2008; Griffero, 2014.

26 Gregg e Seigworth, 2010.

27 Dewsbury, 2015.

28 Connolly, 2002; Anderson, 2014.

29 Daniels, 2015. 
vasividade das tecnologias de comunicação que impulsionaram o movimento de pessoas, bens e representações através do espaço, gerando um 'espaço-movimento' largamente dependente dessas tecnologias ${ }^{30}$. Em análises iniciais, a perceção do aumento do movimento no espaço era visto como uma disrupção da identidade, das relações sociais e do sentido de lugar ${ }^{31}$. Mais recentemente, tem sido argumentado que, embora este 'espaço-movimento' crie novos tipos de consciência espacial, isso não significa o fim da natureza relacional do espaço ou do sentido de lugar ${ }^{32}$. Em particular, é importante salientar que o aumento no movimento não implica a superação do espaço, nem que este deve passar para segundo plano para nos focarmos nos objectos e sujeitos móveis. Segundo McCormack, “(...) o espaço não é redutível ao estatuto de um recipiente tridimensional passivo dentro do qual a ação intencional de um sujeito encorpado móvel decorre" ${ }^{\prime 3}$. Pelo contrário, o espaço é um ator nas dinâmicas da mobilidade, um ator que não só é alterado por corpos que se movem, mas também afeta os movimentos de diferentes formas ${ }^{34}$.

Estes três argumentos têm substanciado um corpo de literatura sobre ritmos espaciais, e mais especificamente sobre ritmos urbanos. A discussão de Lefebvre ${ }^{35}$ sobre ritmos tem sido o ponto de partida para grande parte destes estudos. Segundo McCormack, "o ritmo providencia um modo de pensar o quotidiano como dinâmico, processual e relacional" ${ }^{\prime 36}$, conjugando assim os três argumentos que apresentámos. Estudos sobre ritmos urbanos têm salientado como estes afetam a produção espacial e social ${ }^{37}$, como moldam as paisagens sensoriais e o quotidiano dos residentes $^{38}$, e como são mercadorizados e consumidos ${ }^{39}$. Uma questão central na compreensão dos ritmos urbanos é a tensão entre estrutura e fluidez. Embora os ritmos urbanos sejam marcados por uma estruturação espácio-temporal bastante vincada ${ }^{40}$, eles são também compostos por emergências temporárias que interferem constantemente com essa estrutura. De facto, quando se criam leituras dos ritmos urbanos, é frequentemente aparente que as vidas são vividas num fluxo contínuo imprevisível, dadas as pequenas necessidades e emergências que nos surgem no dia a dia ${ }^{41}$. Apenas a partir de uma perspetiva alargada sobre o uso do espaço ou do tempo se encontram padrões relativamente estáveis. É fruto dessa aparente dicotomia que alguns estudos sobre ritmos urbanos tendem a focar os padrões rítmicos e a sua previsibilidade ${ }^{42}$, enquanto outros sublinham a fluidez e as constantes arritmias

30 Thrift, 2008.

31 Augé, 1992.

32 Massey, 2005; Thrift, 2008.

33 McCormack, 2013, p. 2.

34 Amin, 2008.

35 Lefebvre, 2004.

36 McCormack, 2013, p. 6.

37 Wunderlich, 2008; Vannini, 2012; Lehtuvuori and Koskela, 2013.

38 Simpson, 2008; Vergunst, 2010.

39 Kärrholm, 2009; Degen, 2010.

40 Zerubavel, 1985.

41 Crang, 2001; Edensor, 2010.

42 Pradel, 2010; Marmolejo e Cerda, 2012; Pradel, 2013; Rio Fernandes e Chamusca, 2013; Neuhaus, 
e síncopes dos ritmos urbanos ${ }^{43}$. As disparidades entre os resultados destes estudos são fruto da sua perspetiva: enquanto os primeiros partem de uma perspetiva macro que pretende construir uma visão da cidade a partir de cima, os segundos baseiam-se em observações etnográficas e constroem o seu conhecimento a partir do terreno.

A esta tensão associa-se a dicotomia entre o estudo dos aspectos de atividade e os aspetos sensoriais dos ritmos urbanos. Como Degen ${ }^{44}$ explica, os ritmos urbanos são compostos pela multiplicidade de atividades realizadas em ambiente urbano. Mas a essa camada de atividades físicas, conduzidas pelas pessoas, animais e tecnologias no espaço urbano, acresce uma outra camada sensorial, composta pelos fluxos de informações, afetações, affordances e significados que são uma parte fundamental da ritmicidade urbana ${ }^{45}$. Enquanto os estudos focados na estruturas rítmicas abordam essencialmente as atividades, os estudos de cariz etnográfico têm-se debruçado com maior regularidade nos aspetos sensoriais e de perceção $0^{46}$. Deste modo, existe uma lacuna na literatura, um fosso entre os estudos focados nas estruturas rítmicas e os que focam a fluidez rítmica e sensorial dos espaços urbanos. Nas próximas secções, demonstraremos como mobilizámos a geoetnografia para criar uma abordagem que incorpora estas diferentes dimensões analíticas, e nos permite abordar a vida urbana enquanto conjunto de padrões espácio-temporais, sem deixar de parte as intervenções e emergências temporárias que rompem com esses padrões, ultrapassando assim as limitações metodológicas atuais que têm consequências para o conhecimento produzido.

\section{Ritmos urbanos e Geoetnografia}

Na sua obra seminal sobre ritmanálise, Lefebvre ${ }^{47}$ aponta para uma dupla apreensão do ritmo. Por um lado, a compreensão dos ritmos faz-se a partir do corpo, porque os ritmos interiores do corpo são a referência que temos para os perceber, funcionando "como um metrónomo"48. É a partir do registo rítmico do corpo que os ritmos exteriores nos parecem rápidos ou lentos, contínuos ou sincopados, confusos ou harmoniosos. Ao mesmo tempo, como Vrobel ${ }^{49}$ destaca, os ritmos corporais estão aninhados nos ritmos sociais e naturais, e ajustam-se a estes. Por este motivo, como Lefebvre ${ }^{50}$ sublinha, "enquanto as vidas são vividas e portanto misturadas, elas distinguem-se mal umas das outras". Isto é, na experiência quotidiana dos ritmos, torna-se difícil distinguir adequadamente os padrões rítmicos, e os fluxos de

2015; Marmolejo e Torné, 2015; Mulíček et al., 2015; Mulíček et al. 2016; Kärrholm, 2016.

43 Simpson, 2008; Vergunst, 2010; Vannini, 2012; Lagerkvist, 2013; Goh, 2014; Rodó de Zárate,

2015; Prieto de la Fuente, 2015; Paiva, 2016.

44 Degen, 2010.

45 Simpson, 2008; Lehtuvuori and Koskela, 2013; Dewsbury, 2015.

46 Vergunst, 2010; Kullman e Palludan, 2011; Ortiz e Prats, 2012; Garrido, 2015.

47 Lefebvre, 2004.

48 Lefebvre, 2004, p. 19.

49 Vobrel, 2013.

50 Lefebvre, 2004, p. 27. 
afetação entre ritmos corporais, sociais e naturais. Por esse motivo, a análise dos ritmos, e dos ritmos urbanos em particular, requer a capacidade de nos situarmos dentro do ritmo, mas também de nos afastarmos dele. Como Lefebvre afirma: "de modo a apreender este objeto elusivo, que não é exatamente um objeto, é portanto necessário situarmo-nos simultaneamente dentro e fora dele" ${ }^{\prime 51}$. Esta necessidade, ainda que crie dificuldades à investigação, permite que a análise dos ritmos urbanos se posicione como um meio privilegiado para "sobrepor e justapor as variegadas visões sobre a cidade para percebê-la e representá-la" ${ }^{52}$. Conseguir justapor as visões top-down e bottom-up da cidade é um objetivo de longa data da teoria urbana que nem sempre é alcançado ${ }^{53}$. Como referimos, a literatura atual sobre ritmos urbanos raramente conseguiu este intento, segmentando-se antes em estudos tendencialmente quantitativos que procuram estruturas e padrões e estudos etnográficos que examinam os aspetos sensitivos dos ritmos urbanos. Como Lefebvre argumenta, o "ritmo reúne aspetos e elementos quantitativos, que marcam o tempo e distinguem momentos - e aspetos e elementos qualitativos, que os ligam, fundam as unidades e resultam delas" 54 . Por este motivo, uma abordagem que congrege estes aspetos e elementos quantitativos e qualitativos pode providenciar uma caracterização mais completa dos ritmos urbanos.

Como conseguir então perceber os ritmos urbanos simultaneamente a partir do seu interior e exterior? Seguindo o conselho de Lefebvre, que nos diz que "uma varanda faz este trabalho admiravelmente" 55 , construímos uma metodologia de observação que combina uma visão de cima, a partir de uma janela, com uma visão no terreno, a partir da rua. Este metodologia pode ser caracterizada como uma 'geoetnografia', um termo proposto para caracterizar metodologias que combinam uma análise geográfica com uma perspetiva etnográfica. As definições de geoetnografia são variadas. Alguns autores entendem-na como o uso de informação gerada através de métodos etnográficos como complemento a sistemas de informação geográfica ${ }^{56}$, sendo também mobilizado o termo geo-narrativa ${ }^{57}$. Outros entendem a geo-etnografia como a criação de etnografias com propósitos geográficos, em particular com fim à compreensão da apropriação do espaço por um determinado grupo social ${ }^{58}$. É de sublinhar que a geografia e os geógrafos têm na etnografia um dos seus métodos principais desde a geografia regional ${ }^{59}$, tendo o seu interesse sido ressuscitado recentemente ${ }^{60}$. Porém, o interesse dos geógrafos na etnografia nem sempre é análogo aos dos antropólogos e sociólogos. Enquanto estes dão primazia às pessoas, às comuni-

51 Lefebvre, 2004, p. 27.

52 Tiwari, 2008, p. 305.

53 Lefebvre, 1992; de Certeau, 1984.

54 Lefebvre, 2004, p. 8-9.

55 Lefebvre, 2004, p. 19.

56 Matthews, Detwiler e Burton, 2005; Biffle e Thompson, 2006.

57 Kwan e Ding, 2008.

58 Souza et al., 2009; Nofre et al. 2016.

59 Velasco-Graciet, 2008.

60 Anderson, 2009; ver também Crang e Cook, 2007. 
dades humanas e as suas formas, os geógrafos tendem a dar um maior foco ao lugar, e como este acolhe e substancia as suas comunidades humanas (e não-humanas). No nosso caso, a geoetnografia emerge enquanto uma contraposição de uma análise geográfica alicerçada numa visão de cima, com uma abordagem etnográfica ancorada numa visão a partir do terreno. As duas abordagens informam-se mutuamente, e funcionam para criar um entendimento abrangente dos ritmos urbanos.

Defendemos aqui que a criação de geoetnografias dos ritmos urbanos - nomeadamente a complementaridade entre a visão de cima e a visão a partir do terreno - permite evitar a falácia do 'truque de deus' sobre a qual Haraway ${ }^{61}$ nos avisou. Segunda esta autora, a ciência social tem partido do princípio de que é possível uma perspetiva a partir da qual o conhecimento que emerge é universal e neutro, quando na verdade essa perspetiva é necessariamente localizada e definida em grande parte pelas relações e ideias do investigador. Ao mesmo tempo, a geoetnografia dos ritmos urbanos permite evitar o particularismo e a indeterminação que por vezes impede inferências generalizantes nos estudos urbanos à escala micro ${ }^{62}$.

\section{O Chiado}

O estudo foi realizado na área do Chiado, uma área privilegiada para o consumo e a cultura localizada no centro de Lisboa. O Chiado localiza-se na encosta a Oeste da Baixa de Lisboa e tem uma delimitação difícil. Até 1880, Chiado denominava a rua desde então conhecida como Rua Garrett, uma das ruas mais importantes deste espaço e historicamente um centro de comércio e cultura. Posteriormente, o nome Chiado passou a figurar no Largo do Chiado (ao cimo da Rua Garrett), antes disso conhecido como Largo do Loreto, por aí se localizar a Igreja do Loreto. Em 1925, é colocada neste largo a estátua do poeta António Ribeiro Chiado, um importante ícone da paisagem urbana desta área. Ao longo do século XX, foi ganhando corpo denominar a área constituída pelo Largo do Chiado, a Rua Garrett e as suas transversais, bem como a Rua do Carmo e a Rua Nova do Almada que ligam à Baixa de Lisboa, como Chiado. Isto acontece porque o comércio de qualidade originalmente presente na Rua Garrett expandiu-se por toda esta área, tornando o Chiado numa das principais áreas comerciais da cidade. Como Janeiro63 refere, durante a segunda metade do século XIX e o primeiro quartel do século XX, instalam-se na área do Chiado uma série de estabelecimentos comerciais de referência, como restaurantes, pastelarias e cafés, luveiros, chapeleiros, modistas e alfaiatarias, lojas de confecções e retrosarias, bem como clubes e hotéis. Alguns vendiam produtos de luxo importados, e muitos pertenciam a comerciantes estrangeiros, da Itália ou de França.

Localizam-se aqui também espaços culturais como teatros, cinemas, e livrarias bem como outros locais de encontro de grande importância para a história da cultura lisboeta, como o Grémio Literário, onde emergiu o movimento romantista português, o Casino Lisbonense, onde se reuniam membros do movimento realista, ou o 61 Haraway, 1988.

62 Storper e Scott, 2016.

63 Janeiro, 2006. 
café A Brasileira, um local de encontro importante para o movimento modernista e onde se localiza hoje a estátua do poeta modernista Fernando Pessoa. Muitos destes espaços, como a casa de tabaco importado Casa Havanesa, ou a livraria Bertrand, ainda se encontram abertos hoje. Pela associação à cultura e ao comércio de luxo, o Chiado tem sido detalhado na literatura ficcional como um espaço de ostentação, luxo, moda, e consumo. Ramalho Ortigão chama-lhe a "ladeira vaidosa", e Fialho de Almeida diz-nos que ali se pode observar "a fina essência da elegância"64.

O Chiado passou por um período de declínio desde os anos 60, agravado na década de 1990, após um grande incêndio em 1988 que destruiu vários edifícios na Rua do Carmo e na Rua Garrett onde se encontravam estabelecimentos importantes. O declínio da importância do comércio do Chiado não se deveu apenas ao incêndio mas insere-se no declínio do centro da cidade de Lisboa, devido a perdas de população e à concorrência dos centros comerciais regionais que se foram instalando na periferia de cidade ${ }^{65}$.

Desde o início do presente século, uma série de iniciativas de regeneração, que tinham o objetivo de "transformar esta área num centro comercial ao ar livre"66, renovaram o seu comércio e edificado. Simultaneamente, o aumento do turismo na cidade de Lisboa também contribuiu para mudar o Chiado, que se tornou num ponto de atração turístico de referência. Nas últimas décadas, alguns apartamentos desabitados no Chiado foram convertidos em hostels e o edifício de um antigo Grande Armazém foi convertido em hotel ${ }^{67}$.

Segundo dados de um levantamento realizado pelos autores em 2012, o Chiado continha 218 estabelecimentos, sendo a maioria lojas de comércio (126), distribuídos por vários sectores, embora se verificasse uma predominância da categoria da moda e vestuário. Encontravam-se também no Chiado 39 estabelecimentos ligados à cultura, como museus, galerias, ateliers ou livrarias. O consumo de comida e bebidas também está muito presente, com 44 estabelecimentos desta natureza, incluindo restaurantes, bares ou cafés. Por último, existem 6 estabelecimentos no ramo da hotelaria e 5 estabelecimentos no ramo dos serviços financeiros. Uma parte significativa do comércio atual no Chiado está ligada às grandes cadeias de distribuição internacionais, como a Inditex, embora ainda subsistam várias lojas independentes que iniciaram a sua actividade no século XIX ou no início do século XX.

A escolha do Chiado como caso de estudo prende-se com a sua vivacidade em termos de apropriação do espaço público, gerada pela oferta comercial da área, que o torna numa área que vive "ao ritmo das compras"68. Sendo composto por arruamentos onde a função comercial predomina, o Chiado tem regularmente uma grande densidade de consumidores que sobem e descem as ruas, e entram e saem das lojas, gerando muito movimento na rua. Apenas uma das ruas do Chiado - a Rua

64 Janeiro, 2006, p. 183.

65 Barata-Salgueiro, 2001; Guimarães, 2015.

66 Guimarães, 2015; ver também Balsas, 2007.

67 Abrantes, 2016.

68 Kärrholm, 2009. 
do Carmo - é completamente pedonal, pelo que o tráfego automóvel, e de eléctricos no caso do Largo do Chiado, têm uma presença expressiva, gerando um volume sonoro significante. Por outro lado, a presença do património histórico que referimos, nomeadamente as igrejas e estátuas, torna o Chiado num espaço visualmente atractivo, com uma qualidade estética assinalável. No seu conjunto, o Chiado é um local vibrante com uma atmosfera polirrítmica e multissensorial que lhe confere as qualidades ideais para ser tomado como o locus de um estudo sobre ritmos urbanos.

\section{Uma geoetnografia do Chiado}

A investigação que aqui reportamos iniciou-se em 2012 e prosseguiu até 2016. Num primeiro momento, no âmbito do projeto CHRONOTOPE, construiu-se uma visão de conjunto sobre os ritmos do Chiado, com o propósito de compreender a relação entre os padrões rítmicos dessa área e os horários da oferta comercial, que se completou com uma leitura a partir do terreno. Num segundo momento, no projeto "Som urbano: territórios, atmosferas afetivas e políticas" (SFRH/BD/108907/2015) (2015-2016), construiu-se uma perspetiva a partir do terreno focada em aspectos sensoriais de modo a perceber como eventos temporários interrompem e alteram a estrutura habitual dos padrões rítmicos do Chiado. Nas próximas duas secções, iremos detalhar esta metodologia, ilustrando como a fotografia e o vídeo tiveram um papel fundamental nas duas etapas, e demonstrando o valor desta metodologia para avanços teóricos no campo dos ritmos urbanos.

\section{O Chiado visto de uma janela}

Num primeiro momento, no âmbito do projeto CHRONOTOPE, pretendia-se explorar a relação entre os horários das lojas e os ritmos do espaço público. Nesse período, em 2012 e 2013, realizaram-se dois levantamentos: um sobre os horários das lojas, e o outro dos fluxos do espaço público. O primeiro foi realizado por inquérito, e o segundo baseou-se no registo fotográfico e videográfico do espaço público a partir de uma visão de cima obtida a partir das janelas de andares superiores e de uma ponte de acesso ao ascensor na área do Chiado. O registo fotográfico serviu para efetuar contagens do número de pessoas nas ruas. O método consistiu em tirar cinco fotografias em cada registo, de modo a usar o valor médio. O registo videográfico serviu para identificar os principais fluxos de movimentos, tendo sido realizada uma gravação de 3 minutos em cada registo. O registo foi efetuado de forma sistemática, em horas pré-determinadas do dia (8:00, 10:00, 12:00, 13:00, 14:00, 17:00, 19:00, 20:00 e 22:00), em três dias da semana (Quinta-feira, Sábado e Domingo). Estes registos foram realizados duas vezes, em Dezembro de 2012 e em Maio de 2013, de modo a identificar alterações resultantes das condições atmosféricas (chuva no Inverno e calor na PrimaveralVerão).

Para representar a área do Chiado, foram escolhidos sete arruamentos: Rua do Carmo, Rua Nova do Almada, Rua Garrett, Rua do Sacramento, Largo do Carmo, Largo do Chiado, e Praça de Camões. A escolha destes espaços está relacionada com 
a densidade e simbolismo comercial destas ruas e da localização de alguns marcos como as estátuas dos poetas Fernando Pessoa, António Chiado, e Luís de Camões, e o Convento do Carmo.

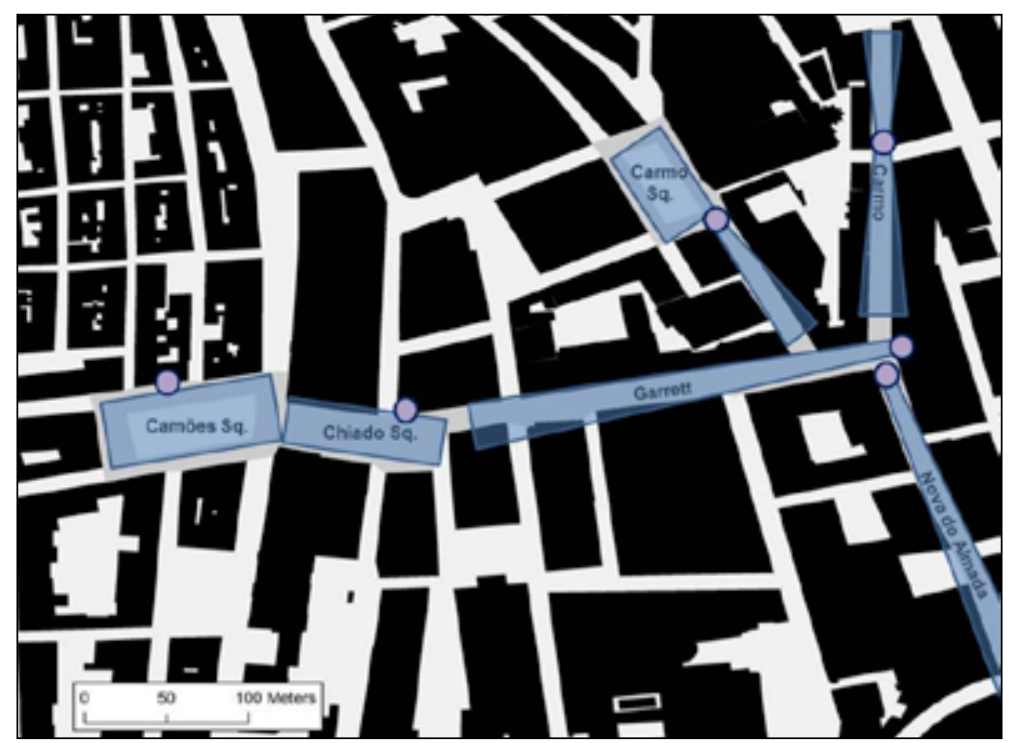

Figura 1. Pontos de captação de fotografia e vídeo "a partir da janela" no Chiado

Fonte: Elaborado pelos autores

A explicação para cingirmos a representação da área a estes arruamentos prende-se com a dificuldade de aceder a locais que confiram uma visão de cima suficiente para captar a totalidade de uma rua. Para realizar as fotografias e vídeos sobre os arruamentos foram utilizados os seguintes pontos de captação: a ponte do Elevador de Santa Justa sobre a Rua do Carmo; a varanda do edifício dos Armazéns do Chiado sobre a Rua Garrett, uma janela do Hostel Lisbon Poets sobre o Largo do Chiado, e

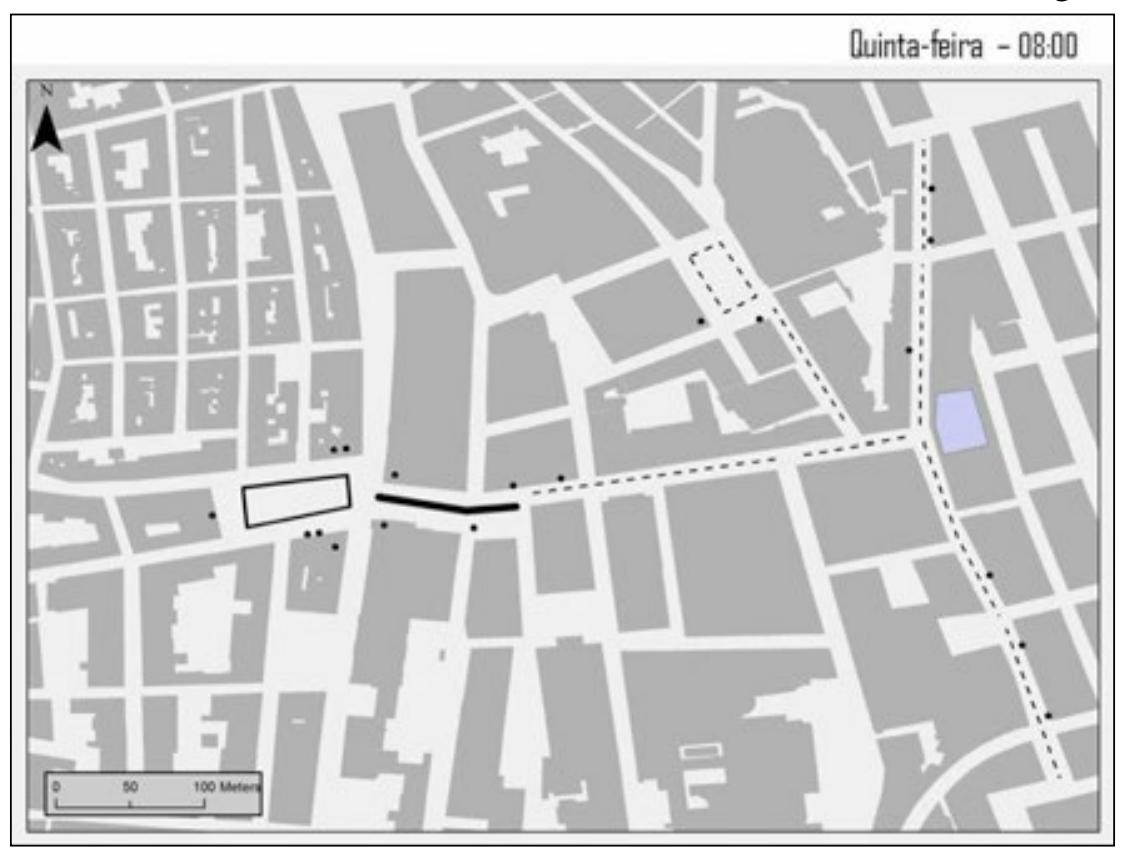

Figura 2. Padrões rítmicos do comércio e apropriação do espaço público no Chiado

Fonte: Elaborado pelos autores 
uma janela do Hostel Passport Boutique sobre a Praça de Camões. Os outros arruamentos - a Rua Nova do Almada, a Rua do Sacramento e o Largo do Carmo - permitiram que a fotografia fosse realizada ao nível da rua devido ao declive acentuado do seu terreno. A figura 1 situa os pontos de captação nas ruas do Chiado.

Tabela 1. Número de pessoas no Largo do Chiado em várias horas do dia nos meses de Abril e Dezembro.

\begin{tabular}{|c|c|c|c|c|c|c|c|c|c|}
\hline & & \multicolumn{2}{|c|}{ Quinta-feira } & \multirow[b]{2}{*}{$10: 00$} & \multirow[b]{2}{*}{$13: 00$} & \multirow[b]{2}{*}{ 14:00 } & \multirow[b]{2}{*}{ 17:00 } & \multirow[b]{2}{*}{ 19:00 } & \multirow[b]{2}{*}{$20: 00$} \\
\hline & & 08:00 & 09:00 & & & & & & \\
\hline \multirow[t]{3}{*}{ Abril } & Indivíduos & $\mathrm{N} \backslash \mathrm{A}$ & 48 & 38 & 42 & 37 & 96,8 & 163,2 & 159 \\
\hline & Temp. & $16^{\circ} \mathrm{C}$ & $18^{\circ} \mathrm{C}$ & $19^{\circ} \mathrm{C}$ & $25^{\circ} \mathrm{C}$ & $25^{\circ} \mathrm{C}$ & $23^{\circ} \mathrm{C}$ & $21^{\circ} \mathrm{C}$ & $19^{\circ} \mathrm{C}$ \\
\hline & Luz & Dia & Dia & Dia & Dia & Dia & Dia & Dia & Dia \\
\hline \multirow[t]{5}{*}{ Dezembro } & Indivíduos & 63 & 76 & 73 & 110 & 77 & 85 & 150 & 95 \\
\hline & Temp. & $7^{\circ} \mathrm{C}$ & $9^{\circ} \mathrm{C}$ & $11^{\circ} \mathrm{C}$ & $14^{\circ} \mathrm{C}$ & $13^{\circ} \mathrm{C}$ & $12^{\circ} \mathrm{C}$ & $11^{\circ} \mathrm{C}$ & $10^{\circ} \mathrm{C}$ \\
\hline & Luz & Dia & Dia & Dia & Dia & Dia & Dia & Noite & Noite \\
\hline & & Sábad & & & & & & & \\
\hline & & 08:00 & 09:00 & $10: 00$ & 13:00 & 14:00 & $17: 00$ & 19:00 & 20:00 \\
\hline \multirow[t]{3}{*}{ Abril } & Indivíduos & $\mathrm{N} \backslash \mathrm{A}$ & $\mathrm{N} \backslash \mathrm{A}$ & 57 & 44,4 & 51,2 & 142,8 & 162 & 256,8 \\
\hline & Temp. & $10^{\circ} \mathrm{C}$ & $12^{\circ} \mathrm{C}$ & $13^{\circ} \mathrm{C}$ & $15^{\circ} \mathrm{C}$ & $15^{\circ} \mathrm{C}$ & $15^{\circ} \mathrm{C}$ & $13^{\circ} \mathrm{C}$ & $12^{\circ} \mathrm{C}$ \\
\hline & Luz & Dia & Dia & Dia & Dia & Dia & Dia & Dia & Dia \\
\hline \multirow[t]{5}{*}{ Dezembro } & Indivíduos & 17 & 55 & 141 & 103 & 119 & 273 & 210 & 172 \\
\hline & Temp. & $7^{\circ} \mathrm{C}$ & $8^{\circ} \mathrm{C}$ & $9^{\circ} \mathrm{C}$ & $12^{\circ} \mathrm{C}$ & $13^{\circ} \mathrm{C}$ & $11^{\circ} \mathrm{C}$ & $10^{\circ} \mathrm{C}$ & $9^{\circ} \mathrm{C}$ \\
\hline & Luz & Dia & Dia & Dia & Dia & Dia & Dia & Noite & Noite \\
\hline & & Domiı & & & & & & & \\
\hline & & 08:00 & 09:00 & $10: 00$ & 13:00 & 14:00 & 17:00 & 19:00 & 20:00 \\
\hline \multirow[t]{3}{*}{ Abril } & Indivíduos & $\mathrm{N} \backslash \mathrm{A}$ & 69,2 & 76,2 & 80,8 & 78,8 & 60,6 & 60 & 71,6 \\
\hline & Temp. & $8^{\circ} \mathrm{C}$ & $10^{\circ} \mathrm{C}$ & $12^{\circ} \mathrm{C}$ & $14^{\circ} \mathrm{C}$ & $14^{\circ} \mathrm{C}$ & $14^{\circ} \mathrm{C}$ & $13^{\circ} \mathrm{C}$ & $12^{\circ} \mathrm{C}$ \\
\hline & Luz & Dia & Dia & Dia & Dia & Dia & Dia & Dia & Dia \\
\hline \multirow[t]{3}{*}{ Dezembro } & Indivíduos & 16 & 15 & 63 & 72 & 74 & 202 & 128 & 211 \\
\hline & Temp. & $6^{\circ} \mathrm{C}$ & $8^{\circ} \mathrm{C}$ & $10^{\circ} \mathrm{C}$ & $12^{\circ} \mathrm{C}$ & $13^{\circ} \mathrm{C}$ & $11^{\circ} \mathrm{C}$ & $9^{\circ} \mathrm{C}$ & $9^{\circ} \mathrm{C}$ \\
\hline & Luz & Dia & Dia & Dia & Dia & Dia & Dia & Noite & Noite \\
\hline
\end{tabular}

Fonte: Elaborado pelos autores

Os dados recolhidos com este método permitiram ainda compreender como os ritmos do Chiado se alteram ao longo do ano consoante as condições atmosféricas. A tabela 1 ilustra essa relação no Largo do Chiado, onde se pode verificar que as horas de exposição solar diurna e as diferentes temperaturas ao longo do dia em Abril e Dezembro contribuem para explicam as variações no número de pessoas no espaço público. Estes dados permitiram uma identificação geral dos padrões dos ritmos do Chiado através da criação de uma imagem de cima. Elaboraram-se uma série de mapas que mostram, em diferentes horas e dias da semana, os estabelecimentos em funcionamento e o número de pessoas em cada arruamento, permitindo assim relacionar as duas variáveis. Estas mapas estão condensados num ficheiro Graphic Interchange Format na figura 2, onde se pode verificar os padrões rítmicos do Chiado ao longo do dia e da semana. 
Tabela 2 - Elementos participantes nos ritmos urbanos do Chiado

\begin{tabular}{|c|c|c|c|c|c|c|}
\hline & 8 horas & 10 horas & 13 horas & 17 horas & 19 horas & 22 horas \\
\hline Utilizadores & $\begin{array}{l}\text { Adultos; Tra- } \\
\text { balhadores. }\end{array}$ & $\begin{array}{r}\text { Adultos; } \\
\text { Crianças; } \\
\text { Idosos; } \\
\text { Pedintes; } \\
\text { Vendedores } \\
\text { de rua; } \\
\text { Turistas. }\end{array}$ & $\begin{array}{r}\text { Adultos; } \\
\text { Crianças; } \\
\text { Jovens; } \\
\text { Pedintes; } \\
\text { Vendedores } \\
\text { de rua; } \\
\text { Turistas. }\end{array}$ & $\begin{array}{r}\text { Adultos; } \\
\text { Crianças; } \\
\text { Idosos; } \\
\text { Jovens; Tra- } \\
\text { balhadores; } \\
\text { Pedintes; } \\
\text { Vendedores } \\
\text { de rua; } \\
\text { Performers; } \\
\text { Turistas. }\end{array}$ & $\begin{array}{r}\text { Adultos; } \\
\text { Casais com } \\
\text { carros de } \\
\text { bebé; } \\
\text { Crianças; } \\
\text { Idosos; } \\
\text { Jovens; Tra- } \\
\text { balhadores; } \\
\text { Pedintes; } \\
\text { Vendedores } \\
\text { de rua; } \\
\text { Performers; } \\
\text { Turistas. }\end{array}$ & $\begin{array}{r}\text { Adultos; } \\
\text { Jovens; } \\
\text { Vendedores } \\
\text { de rua; } \\
\text { Turistas }\end{array}$ \\
\hline Ritmos & Rápidos & Polirritmia & Polirritmia & Polirritmia & Polirritmia & Lento \\
\hline $\begin{array}{l}\text { Movimentos } \\
\text { Tempo- } \\
\text { Espaço }\end{array}$ & $\begin{array}{l}\text { Pouco movi- } \\
\text { mento. }\end{array}$ & $\begin{array}{r}\text { Parados; Pas- } \\
\text { sar; Passear; } \\
\text { Carros e } \\
\text { eléctricos a } \\
\text { cruzar a área. }\end{array}$ & $\begin{array}{r}\text { Parados; Pas- } \\
\text { sar; Passear; } \\
\text { Carros e } \\
\text { eléctricos a } \\
\text { cruzar a área. }\end{array}$ & $\begin{array}{r}\text { Parados; Pas- } \\
\text { sar; Passear; } \\
\text { Carros e } \\
\text { eléctricos a } \\
\text { cruzar a área. }\end{array}$ & $\begin{array}{r}\text { Parados; Pas- } \\
\text { sar; Passear; } \\
\text { Carros e } \\
\text { eléctricos a } \\
\text { cruzar a área. }\end{array}$ & $\begin{array}{l}\text { Parados; Pas- } \\
\text { sar; Passear; } \\
\text { Carros a cru- } \\
\text { zar a área. }\end{array}$ \\
\hline Práticas & $\begin{array}{r}\text { Deslocação; } \\
\text { Esperar } \\
\text { transportes; } \\
\text { Pequeno-al- } \\
\text { moço/café. }\end{array}$ & $\begin{array}{r}\text { Deslocação; } \\
\text { Passear; Es- } \\
\text { perar trans- } \\
\text { portes; } \\
\text { Café/bebi- } \\
\text { das; } \\
\text { Conversar; } \\
\text { Passar o } \\
\text { tempo; } \\
\text { Compras; Ver } \\
\text { montras; Ver } \\
\text { performan- } \\
\text { ces de rua. }\end{array}$ & $\begin{array}{r}\text { Deslocação; } \\
\text { Passear; Es- } \\
\text { perar trans- } \\
\text { portes; } \\
\text { Café/bebi- } \\
\text { das; Almoço; } \\
\text { Conversar; } \\
\text { Passar o } \\
\text { tempo; } \\
\text { Compras; Ver } \\
\text { montras; Ver } \\
\text { performan- } \\
\text { ces de rua. }\end{array}$ & $\begin{array}{r}\text { Deslocação; } \\
\text { Passear; Es- } \\
\text { perar trans- } \\
\text { portes; } \\
\text { Café/bebi- } \\
\text { das; } \\
\text { Conversar; } \\
\text { Passar o } \\
\text { tempo; } \\
\text { Compras; Ver } \\
\text { montras; Ver } \\
\text { performan- } \\
\text { ces de rua. }\end{array}$ & $\begin{array}{r}\text { Deslocação; } \\
\text { Passear; Es- } \\
\text { perar trans- } \\
\text { portes; } \\
\text { Café/bebi- } \\
\text { das; } \\
\text { Conversar; } \\
\text { Passar o tem- } \\
\text { po; Compras; } \\
\text { Ver montras; } \\
\text { Ver perfor- } \\
\text { mances de } \\
\text { rua. }\end{array}$ & $\begin{array}{r}\text { Passear; } \\
\text { Café/bebi- } \\
\text { das; } \\
\text { Conversar; } \\
\text { Passar o } \\
\text { tempo; }\end{array}$ \\
\hline Recursos & $\begin{array}{l}\text { Ruas; Para- } \\
\text { gem de eléc- } \\
\text { trico; Estação } \\
\text { do metropo- } \\
\text { litano; Cafés. }\end{array}$ & $\begin{array}{r}\text { Paragem de } \\
\text { eléctrico; } \\
\text { Estação do } \\
\text { metropolita- } \\
\text { no; Cafés; } \\
\text { Património } \\
\text { arquitectó- } \\
\text { nico; } \\
\text { Lojas; } \\
\text { Mobiliário } \\
\text { urbano; }\end{array}$ & $\begin{array}{r}\text { Paragem de } \\
\text { eléctrico; } \\
\text { Estação do } \\
\text { metropoli- } \\
\text { tano; Cafés/ } \\
\text { restaurantes; } \\
\text { Património } \\
\text { arquitectó- } \\
\text { nico; } \\
\text { Lojas; } \\
\text { Mobiliário } \\
\text { urbano; }\end{array}$ & $\begin{array}{r}\text { Paragem de } \\
\text { eléctrico; } \\
\text { Estação do } \\
\text { metropolita- } \\
\text { no; Cafés; } \\
\text { Património } \\
\text { arquitectó- } \\
\text { nico; } \\
\text { Lojas; } \\
\text { Mobiliário } \\
\text { urbano; } \\
\text { Performan- } \\
\text { ces de rua. }\end{array}$ & $\begin{array}{r}\text { Paragem de } \\
\text { eléctrico; } \\
\text { Estação do } \\
\text { metropolita- } \\
\text { no; Cafés; } \\
\text { Património } \\
\text { arquitectó- } \\
\text { nico; } \\
\text { Lojas; } \\
\text { Mobiliário } \\
\text { urbano; } \\
\text { Performan- } \\
\text { ces de rua. }\end{array}$ & $\begin{array}{r}\text { Ruas; Para- } \\
\text { gem de eléc- } \\
\text { trico; Estação } \\
\text { do metropo- } \\
\text { litano; Cafés; } \\
\text { Património } \\
\text { arquitectó- } \\
\text { nico; } \\
\text { Mobiliário } \\
\text { urbano; }\end{array}$ \\
\hline
\end{tabular}

Fonte: Elaborado pelos autores

Num segundo momento, realizou-se observação direta ao nível do terreno. Esta dividiu-se em duas fases. A primeira em 2014, ainda no âmbito do projeto CHRONOTOPE destinou-se à identificação dos principais grupos sociais presentes no es- 
paço público, as suas práticas, bem como as amenidades que são utilizadas, com o objetivo de aprofundar a caracterização dos padrões rítmicos do Chiado. Estas observações foram realizadas nas mesmas horas em que foram realizados os registos fotográficos e videográficos. Nestas observações, o investigador efetuou um registo escrito durante dez minutos de tudo o que se passava no espaço público, às horas pré-determinadas do dia (8:00, 10:00, 12:00, 13:00, 14:00, 17:00, 19:00, 20:00 e 22:00).

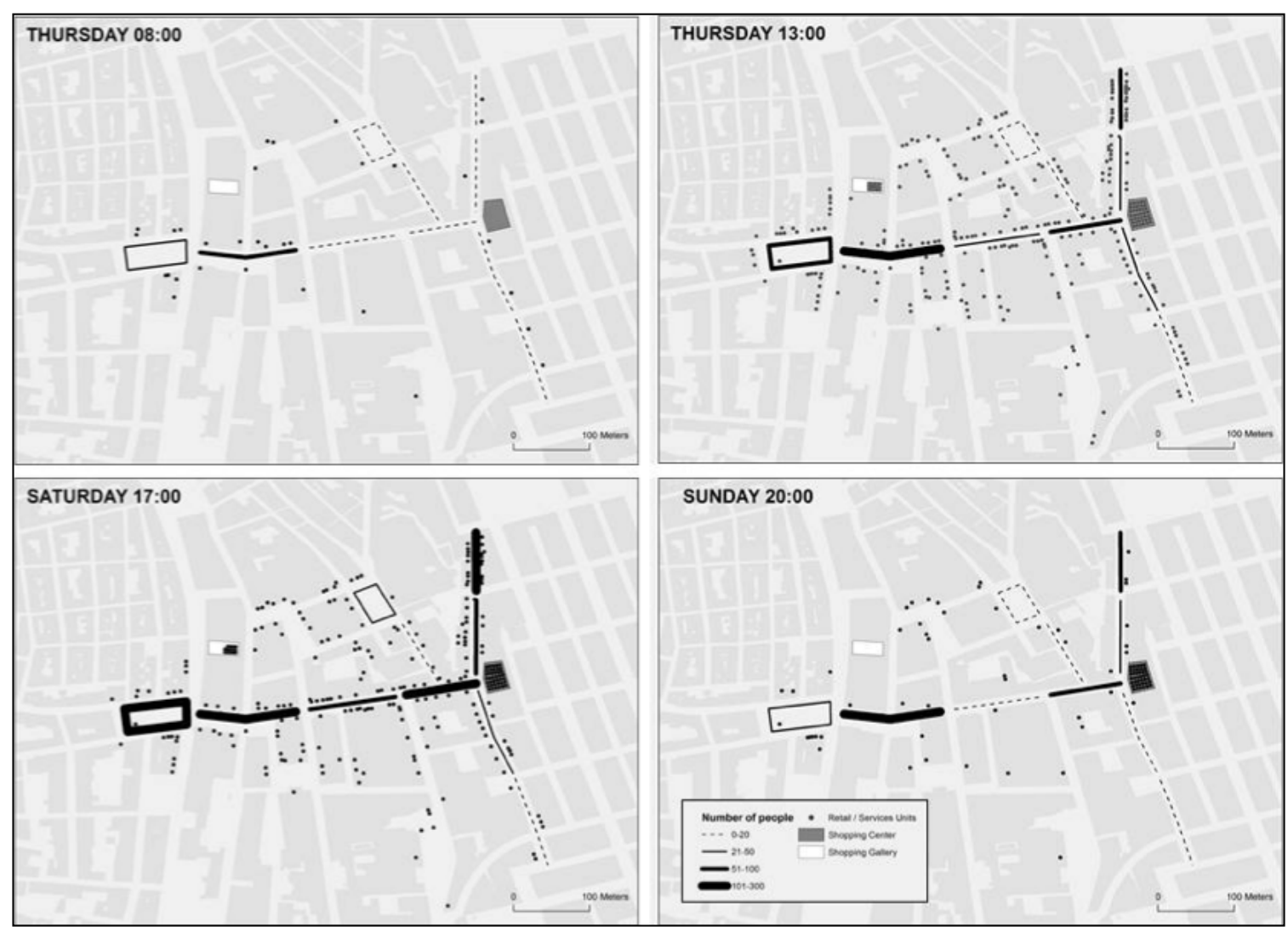

Figura 3. Número de pessoas por arruamento e estabelecimentos abertos no Chiado em diferentes horas e dias da semana Fonte: Elaborado pelos autores

Os registos escritos foram posteriormente sujeitos a uma análise de conteúdo. Criaram-se cinco categorias semânticas para caracterizar as principais componentes dos ritmos do espaço público: utilizadores, ritmos, movimentos tempo-espaço, práticas e recursos. A categoria utilizadores engloba toda a semântica utilizada para descrever os humanos no espaço público (devido à característica do espaço urbanizado, não foram considerados animais). A categoria ritmos reúne a semântica utilizada para descrever a cadência dos ritmos urbanos, que pode ser rápida, lenta, ou polirritmica ${ }^{69}$. A categoria movimentos tempo-espaço engloba a semântica relativa aos elementos do espaço urbano que se movem e o atravessam. A categoria práticas refere-se à semântica que descreve as atividades dos utilizadores que permanecem no lugar (i.e. que não o atravessam e que permanecem nele durante a duração do momento de registo). Estas duas categorias emergem da distinção que Seamon ${ }^{70}$ faz en-

69 Ver Lefebvre, 2004; também Paiva, Cachinho e Barata-Salgueiro, 2016.

70 Seamon, 1980. 
tre movimentos tempo-espaço e práticas espaciais como os dois tipos de movimentos que se conjugam nos ritmos urbanos, a que ele chama place ballets. Por último, a categoria recursos sintetiza a semântica utilizada para identificar as materialidades do espaço urbano que são utilizadas pelos indivíduos, incluindo estabelecimentos, mobiliário urbano, monumentos, transportes, entre outros. A tabela 2 sintetiza os principais elementos dos ritmos urbanos. Estes dados permitem caracterizar os ritmos urbanos em termos socioculturais em dadas horas, o que nos oferece um entendimento mais aprofundado sobre as variações na densidade de indivíduos ao longo do dia. A figura 3 mostra quatro momentos que seleccionámos para ilustrar as possíveis inferências que se podem retirar da conjugação desta informação com a informação espacial.

A relação entre os ritmos da rua, a oferta comercial, e as amenidades de cada arruamento da área está patente nos quatro momentos. Na manhã de Quinta-feira, o lugar com maior densidade de indivíduos é o Largo do Chiado, local onde se localiza a entrada da estação do Metropolitano de Lisboa, meio privilegiado pelos trabalhadores da área na deslocação para o local de trabalho. O facto de a maior parte dos estabelecimentos ainda se encontrarem fechados explica o menor número de indivíduos nos outros arruamentos. Durante a hora de almoço do mesmo dia, verifica-se um panorama diferente: os estabelecimentos estão quase todos abertos e as ruas estão cheias de pessoas. O Largo do Chiado é novamente o local com maior número de indivíduos, o que se explica pelo facto de se encontrarem uma série de restaurantes de referência nos arruamentos próximos. Na tarde de Sábado, novamente o panorama muda novamente. Encontramos na Rua Garrett, na Rua do Carmo e na Praça de Camões uma densidade de indivíduos semelhante àquela do Largo do Chiado. Enquanto na Rua Garrett e na Rua do Carmo o movimento é, em grande medida, gerado pela procura das lojas de elevado estatuto afetas aos artigos pessoais, na Praça de Camões e no Largo do Chiado, é o espaço público em si, apropriado pelos turistas, que mais contribui para o sucedido. No Domingo, ao fim do dia, devido ao menor número de estabelecimentos abertos, encontramos menos indivíduos nas ruas, embora ainda com alguma relevância da Rua do Carmo e Rua Garrett, onde algumas lojas têm horários mais alargados. O espaço público é então mais apropriado por turistas e famílias que passeiam, sendo o Largo do Chiado ainda um local priveligiado.

\section{O Chiado a partir da rua}

A segunda fase de observação ao nível do terreno realizou-se em 2016, já no âmbito do projeto "Som urbano: territórios, atmosferas afetivas e políticas" (SFRH/ $\mathrm{BD} / 108907 / 2015)$, e teve como objetivo perceber como os padrões rítmicos do Chiado são interrompidos ou alterados por eventos temporários. Mais concretamente, pretendia-se compreender como intervenções nas atmosferas afetivas do Chiado tinham a capacidade de alterar os seus ritmos. O conceito de atmosferas afetivas refere-se àquilo que está «entre» no espaço urbano, o terreno partilhado onde os 
afetos se transmitem e são captados pelos diversos sentidos ${ }^{71}$. Segundo Degen ${ }^{72}$, é através dos sentidos que a vida pública é pontuada e produzida, e estes captam tanto as atividades rítmicas do espaço público como as suas materialidades estáveis. Estes processos perfazem aquilo que Stewart ${ }^{73}$ chama 'sintonização atmosférica'. Segundo a autora, "na expressividade de algo a tornar-se existente, os corpos trabalham para literalmente alinharem-se com o andamento, os hábitos, as linhas de pertença, as responsabilidades assumidas, a senciênscia de um mundo emergente" ${ }^{\prime \prime 7}$. Por este motivo, é importante abordar os sentidos no estudo dos ritmos urbanos, em especial a audição, frequentemente referida como um sentido fundamental para captar os ritmos da cidade ${ }^{75}$. Tem sido argumentado que o som é um meio priveligiado para aceder e analisar um ritmo, porque "a paisagem sonora de um lugar urbano (...) desempenha um papel vital na sua perceção"76 e, consequentemente, "os sons evocam a presença da rua bastante bem"77.

No caso do Chiado, as intervenções nas atmosferas afetivas são geralmente performances realizadas por artistas de rua ou manifestações políticas. Mobilizando o conceito de distribuição dos sentidos de Rancière ${ }^{78}$, que aponta para a capacidade de práticas artísticas alterarem o campo do político ao atuarem sobre os sentidos e assim alterarem o que é visível e audível, procurou-se compreender como as performances artísticas neste local têm a capacidade de modificar a estrutura rítmica do espaço ao redistribuírem os sentidos dominantes das suas atmosferas afetivas. Este objetivo obriga a uma nova abordagem em termos de método, sendo necessário um que permita identificar o emergente, a interrupção, a anomalia rítmica que quebra o padrão.

Com isso em mente, nesta fase da investigação procedeu-se à observação prolongada da apropriação do espaço público, usando registos escritos, fotografia e videografia como meio complementar de registo das práticas no espaço público. A observação foi realizada na rua por períodos de duas a três horas, entre as 12 e as 19 horas de dias da semana, por ser nesses momentos que mais performances artísticas ocorrem no Chiado. A escolha de períodos de observação alargados prende-se com a noção de que os ritmos urbanos não existem num presente fixo, mas ocorrem "num fluir de tempo e espaço"79.

Nesta observação, pretendia-se tirar partido da posição situada do investigador, mobilizando o seu próprio sensorium para perceber as dinâmicas afetivas do espaço público. O corpo do investigador neste método é um participante dos ritmos urbanos. Não só é o meio de captação dos fluxos afetivos do espaço público, como

71 Anderson, 2014.

72 Degen, 2010.

73 Stewart, 2011.

74 Stewart, 2011, p. 452.

75 Lefebvre, 2004; Vergunst, 2010; Wunderlich, 2013; Doughty e Lagerqvist, 2016; Simpson, 2016.

76 Wünderlich, 2008, p. 51.

77 Vergunst, 2010, p. 376.

78 Rancière, 2004.

79 Vergunst, 2010, p. 382. 
participa neles, tomando a posição dos diversos sujeitos no espaço urbano: o sujeito que anda, o sujeito que se senta na esplanada e consome, o sujeito que espera uma pessoa em pé, o sujeito que fotografa. Em suma, este método pretende deixar o investigador exposto, usando o seu corpo para percepcionar os fluxos afetivos ${ }^{80}$. Usando o sensorium do investigador, neste caso principalmente o aparelho auditivo e visual, pretende-se não apenas registar os estímulos sensoriais que emergem da ritmicidade urbana, mas também os possíveis impactos corporais (emocionais, cognitivos, e fisiológicos) que podem emergir a partir de cada estímulo ${ }^{81}$. Esta abordagem segue os princípios da etnografia sensorial ${ }^{82}$. Segundo Pink, a etnografia sensorial "é uma metodologia crítica, que (...) parte da abordagem observacional clássica (...) e insiste que a etnografia é um processo reflexivo e experencial através do qual a compreensão, o conhecer e o conhecimento (académico) são produzidos"83. A etnografia sensorial faz uso da experiência sensorial do investigador como meio de captar e compreender "as experiências, modos de conhecer e categorias, significados e práticas sensoriais de outras pessoas" ${ }^{\prime 4}$. Neste âmbito, tem sido argumentado que a abordagem sensorial não se cinge ao estudo das reacções corporais e psicológi$\operatorname{cas}^{85}$. Pelo contrário, os sentidos têm que ser entendidos de um ponto de vista "enraízado"86. Para Howes ${ }^{87}$, o "enraizamento" aumenta o conceito de "incorporação"88. Enquanto "incorporação" segere a integração da mente e corpo numa só entidade, a noção de "enraízamento" chama a atenção para as constantes relações entre mente, corpo e ambiente.

Neste âmbito, o registo fotográfico e videográfico assume uma nova função: a de servir como auxílio afetivo de memória para o investigador. Como apontado por alguns autores, a gravação de imagens e sons não é uma mera representação de um determinado ambiente, e pode funcionar como meio de acionar a memória, especialmente no que toca a sensações corporais ${ }^{89}$. A gravação pode assim ser compreendida como um exemplo de terciarização de memória, um conceito desenvolvido por Stiegler ${ }^{90}$ que se refere ao uso de tecnologias como repositório da memória humana, que se acrescenta à perceção e à lembrança. Deste modo, a utilização de fotografia e videografia não foi estruturada. A fotografia foi mobilizada para captar cenas específicas de um modo rápido, e.g. uma interação entre pessoas, ou entre pessoas e materialidades urbanas. Por outro lado, a videografia foi mobilizada para registar eventos significantes. A sua importância está ligada não só ao facto de captar o evento na totalidade da sua duração mas também de registar a visualidade e a

80 Greenhough, 2010; McCormack, 2013.

81 Longhurst, Ho and Johnston, 2008.

82 Stoller, 1989; 1997.

83 Pink, 2009, p. 8.

84 Pink, 2009, p. 46.

85 Pink, 2009; Vannini, Waskul, e Gottschalk, 2011.

86 Traduzimos aqui o conceito "emplaced" como "enraízado".

87 Howes, 2005.

88 Traduzimos deste modo o conceito "embodiment".

89 Duffy and Waitt, 2011; Gallagher, 2015, Spinney, 2015.

90 Stiegler, 2010. 
sonoridade das práticas, permitindo um registo satisfatório de estímulos sensoriais. De modo a alternar rapidamente entre os dois modos de registo, foi utilizada uma câmara digital com os dois modos.

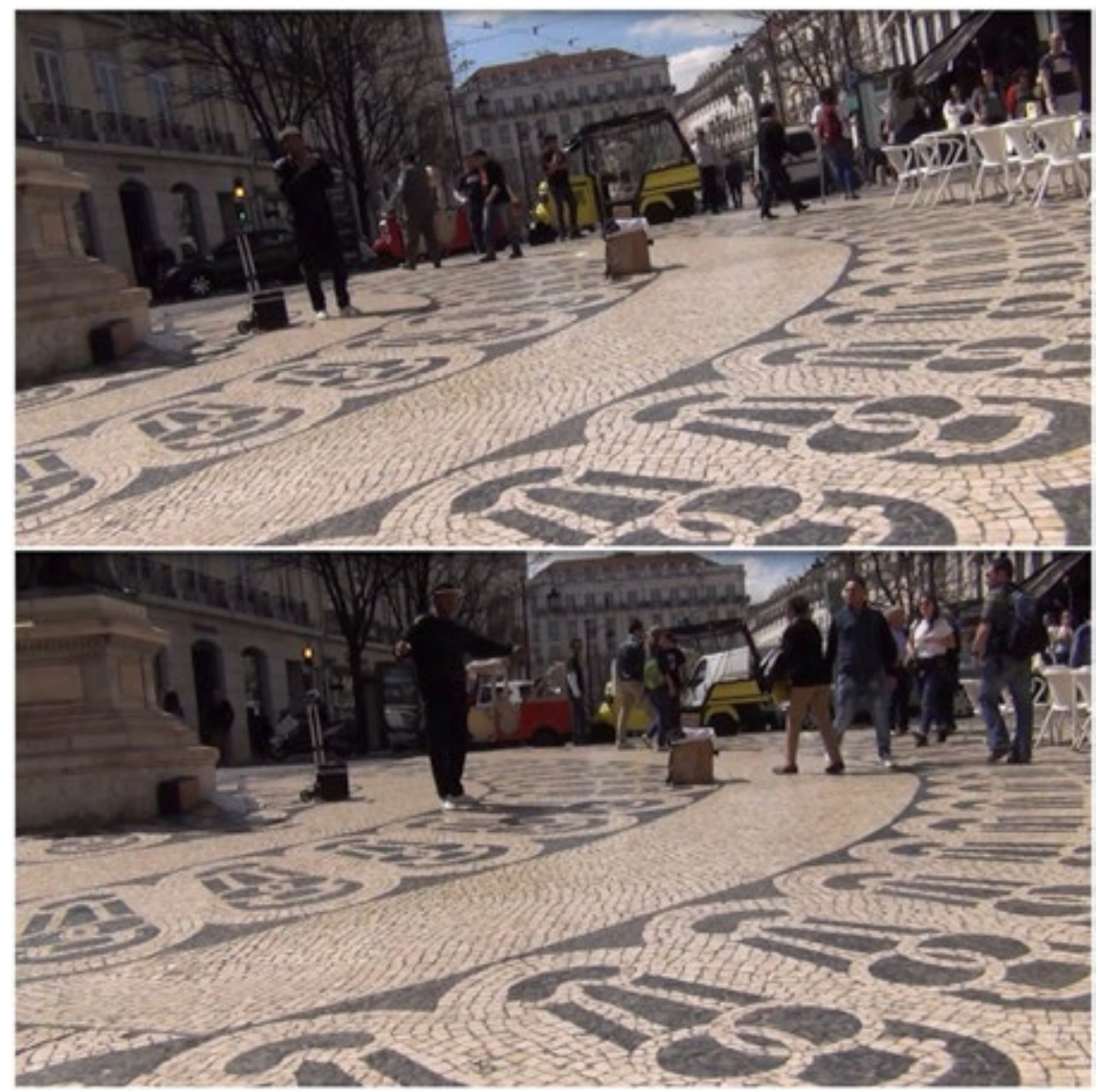

Figura 04. Início de performance de dança no Largo do Chiado. 6 de Abril de 2016

Fonte: Elaborada pelos autores

A experiência no terreno permitiu-nos compreender como as performances artísticas intervêem nos ritmos urbanos, ao redistribuírem os sentidos dominantes do espaço urbano. As performances artísticas - que alternam entre dança e música - conferem um elemento sonoro ao espaço urbano que rompe com os ritmos dominantes da rua. Por um lado, a visualidade dominante do espaço, que advém das montras e da monumentalidade de algum edificado, é interrompida pela sonoridade dominante da música e da dança. Historicamente, o Chiado tem sido um espaço de consumo, marcado pelo 'ritmo das compras' ${ }^{\prime 1}$, onde se tem localizado o comércio de referência da cidade de Lisboa. Enquanto espaço de consumo, tem sido também um espaço primariamente visual, com o visionamento de montras a ser uma parte significante da experiência do espaço público, como Barata-Salgueiro o referiu: “[a ] té aqui há 20 ou 30 anos passeava-se ao sábado à tarde no Chiado de Lisboa onde multidões se cruzavam na actividade de ver montras e pessoas; ver e ser visto" ${ }^{\prime 2}$. Por outro lado, enquanto um lugar que recentemente se tornou um espaço turístico de

91 Kärrholm, 2009.

92 Barata-Salgueiro, 1989, p.154. 
referência ${ }^{93}$, o Chiado é também dominado pelo 'olhar turístico'94, que busca monumentos ou espaços visuais monumentais para presenciar. A performance artística, no entanto, vem redistribuir a sensorialidade do Chiado. A música e a dança conferem um novo ritmo ao espaço público, e os corpos alinham-se a esse ritmo, criando novas socialidades e espacialidades.

As figuras 4 e 5 mostram alguns frames de um video de performances no Largo do Chiado. O frame superior de cada imagem mostra o minuto inicial de cada performance, enquanto o frame inferior mostra um momento no decorrer da performance.

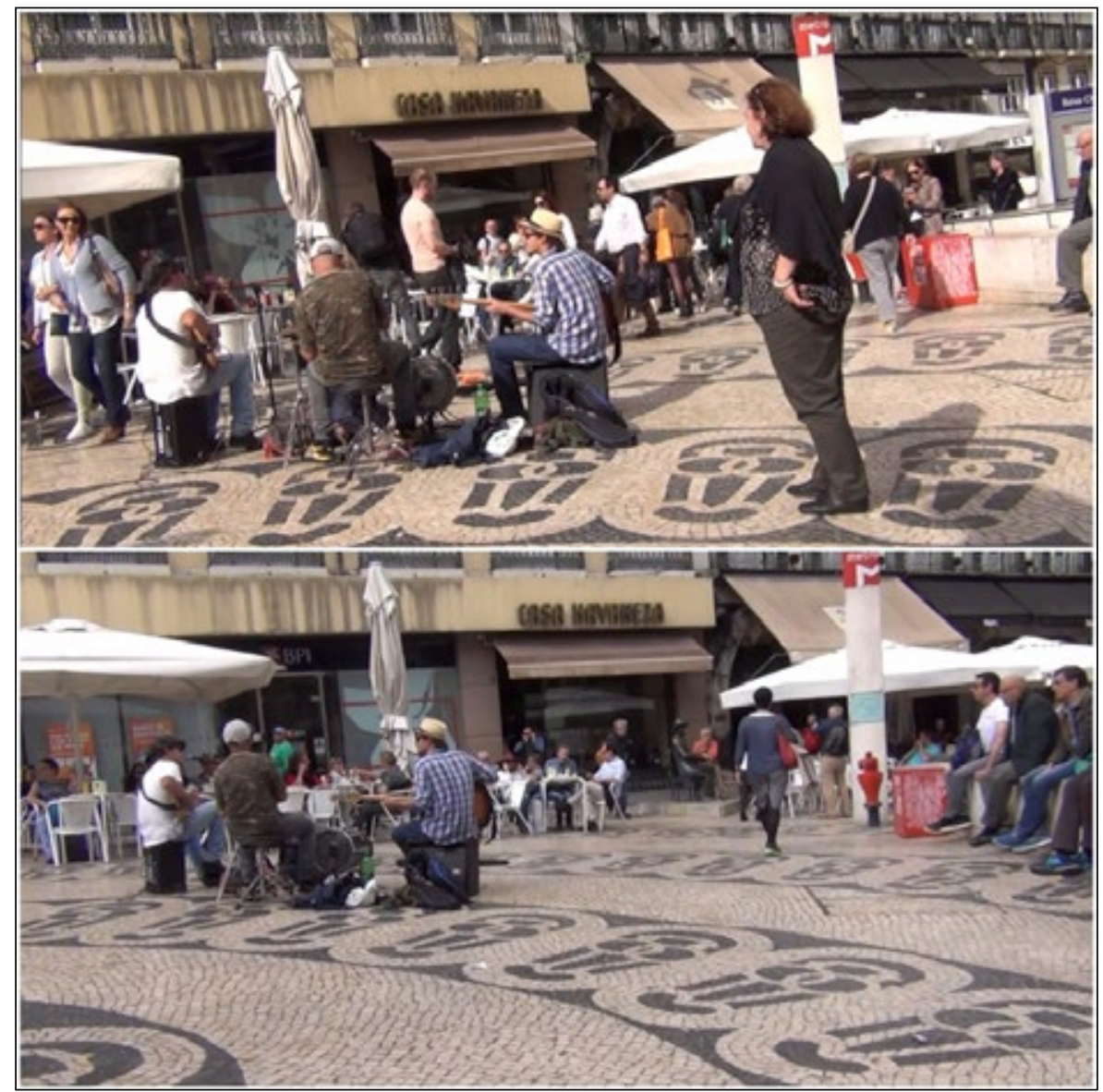

Figura 05. Início de performance musical no Largo do Chiado. 7 de Abril de 2016

Fonte: Elaborada pelos autores

A performance da figura 4 é um espetáculo de dança realizado por apenas um artista, vestido de negro, com o auxílio de música emitida por uma coluna que se vê do lado esquerdo do artista. A performance começa com uma peça de piano que a certo momento replica os acordes de uma conhecida balada romântica. $\mathrm{O}$ dançarino começa a sua rotina, com gestos lentos e suaves, semelhantes aos de uma marioneta, que acompanham o ritmo meloso da música. À medida que as pessoas reconhecem a música, a atenção começa a focar-se no corpo do dançarino - o único que está sintonizado com o andamento e o sentimento da música. As pessoas que andam

93 Abrantes, 2016.

94 Urry e Larsen, 2012. 
abrandam o passo e olham para o dançarino, como o frame inferior da figura 4 mostra. Aqueles que estão sentados na espalanadas ou junto à entrada do metro também observam a performance. À medida que a performance decorre, o ritmo da rua sintoniza-se com o ritmo da performance. Forma-se um círculo de pessoas que pára, senta-se, observa, ouve, dança, sorri, e aprecia o espetáculo.

A performance da figura 5 é um concerto de música executado por uma banda com três elementos que se sentam próximos uns dos outros em cima das colunas dos seus instrumentos. Em contraste com a performance do dançarino, esta não capta imediatamente a atenção das pessoas que passam ou que estão sentadas. A natureza sónica da performance, à qual falta a forte componente visual da dança, não é percebida de imediato num espaço eminentemente visual como o Largo do Chiado. Mas a sintonização atmosférica acontece. Durante o concerto, o ritmo das músicas pop alinha-se com a velocidade dos pedestres, e o volume das colunas é suficiente para mascarar os sons da rua. O timbre agradável é valorizado pelos pedestres e consumidores. Como é visível no frame superior da figura 5, a atenção de algumas pessoas é captada pela banda e alguns começam a aproximar-se ao longo do tempo. Entre as músicas, as pessoas na esplanada que pareciam não prestar atenção à música começam a bater palmas. Na entrada do metro, as pessoas começam a sentar-se para ouvir a música, como se vê no frame inferior da figura 5.

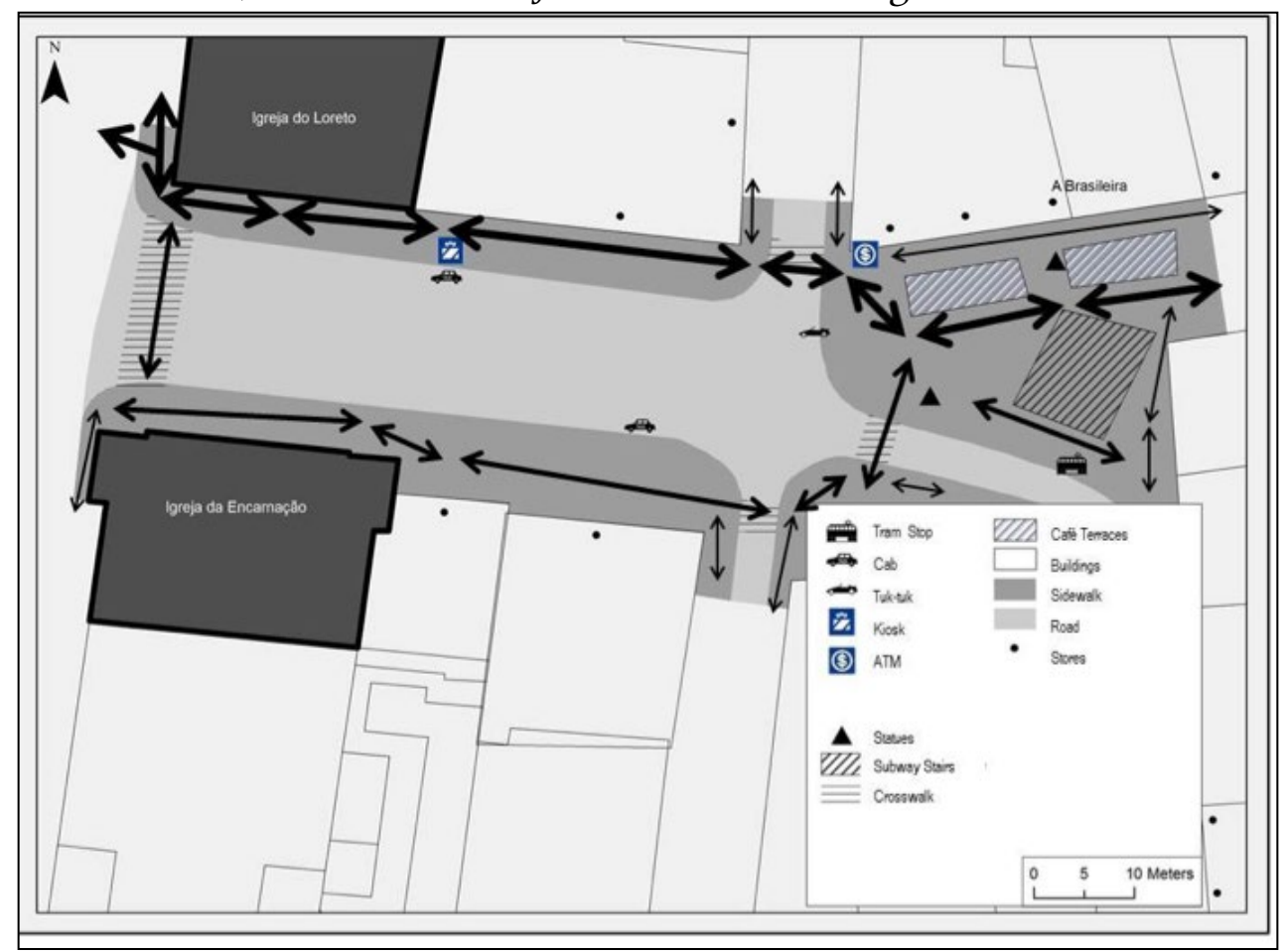

Figura 6. Trajetórias pedestres habituais no Largo do Chiado

Fonte: Elaborado pelos autores

Durante as duas performances, o Largo do Chiado torna-se num espaço sonoro, e a atenção dos indivíduos é captada através da vibração sónica. Deste modo, o que era um espaço primariamente visual depois de alguns minutos torna-se num espaço particularmente sónico. À medida que as performances artistícas redistribuem os 
sentidos no Largo do Chiado, afetam também a distribuição dos corpos humanos pelo espaço e pelo tempo, intervindo sobre os ritmos do espaço urbano. Entre o início e o fim da cada performance, o Largo do Chiado tem uma distribuição de trajetórias e apropriações distintas.

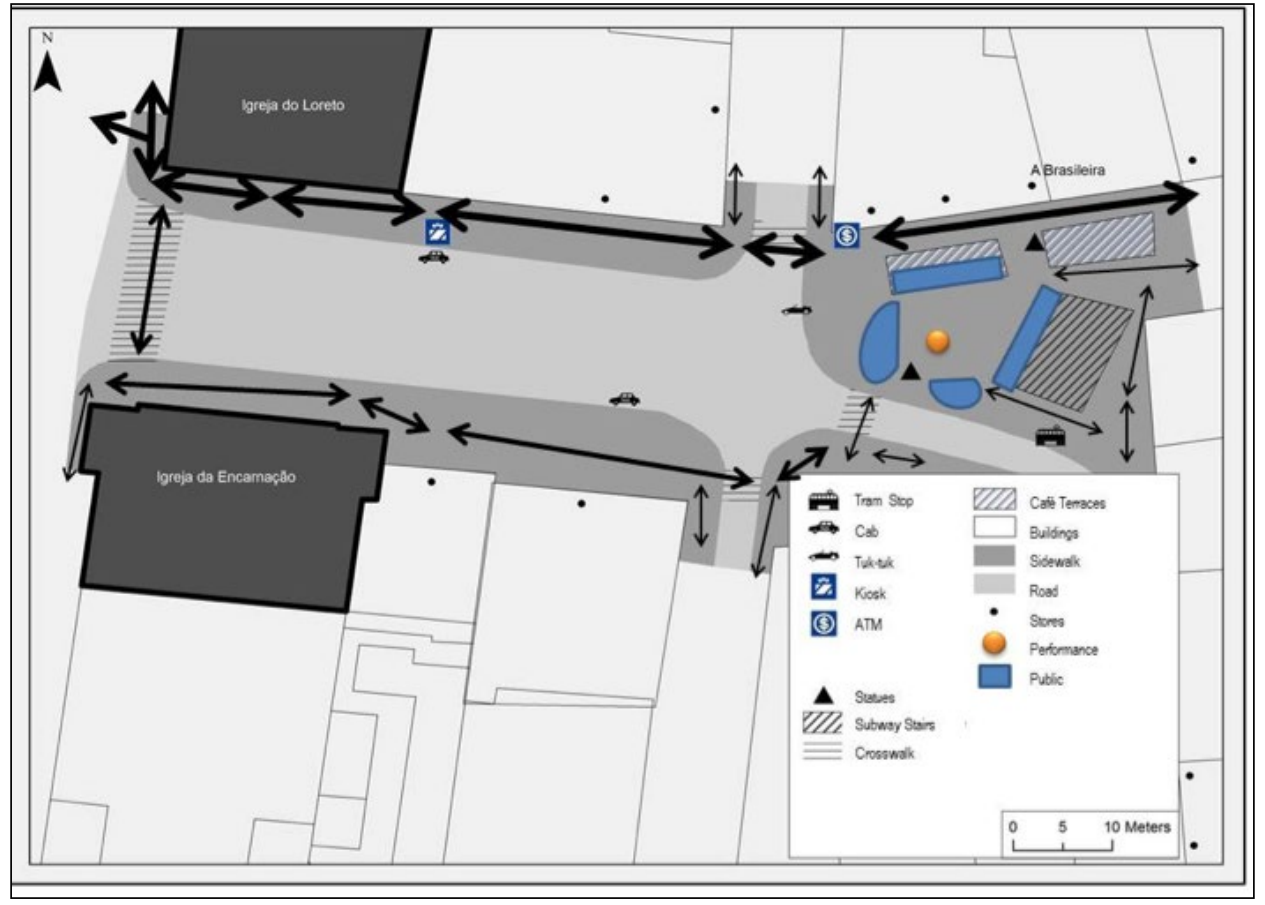

Figura 7. Trajetórias pedestres no Largo do Chiado durante performances artísticas

Fonte: Elaborado pelos autores

Com esta informação qualitativa, a visão sobre os padrões dos ritmos urbanos que criámos 'a partir da janela' é também reformulada, podendo gerar-se novos mapeamentos, mais maleáveis, que mostram uma apropriação do espaço urbano que se transfigura à medida que os elementos móveis do espaço urbano se instalam ou se deslocam. Esta ideia é ilustrada nas figuras 6 e 7. A figura 6 mostra as trajetórias habituais no Largo do Chiado, enquanto a figura 8 mostra as trajetórias e as apropriações espaciais durante as performances artísticas. Como se pode visualizar, as performances artísticas não só clamam para si um espaço de permanência e apropriação nas esplanadas, na entrada do metro e na própria rua, como também obrigam a que os principais fluxos de movimentos se façam por outros percursos.

\section{O uso de fotografia e video na criação de etnografias}

A construção de ambas as perspetivas recorre ao uso de tecnologias de registo da vida urbana, nomeadamente a fotografia e o video, sem as quais a tarefa seria muito mais dificultada. O uso de fotografia e video na construção de etnografias tem uma história longa e coesa ${ }^{95}$, e a sua utilidade no estudo dos ritmos urbanos tem sido sublinhada ${ }^{96}$. A sua mobilização no nosso estudo demonstra as múltiplas possibilida-

95 Rose, 2007; Pink, 2007.

96 Wunderlich, 2008; Simpson 2012; Kärrholm, 2015; Prieto de la Fuente, 2015. 
des que estas tecnologias providenciam, bem como as possibilidades que emergem do seu uso em técnicas diferentes. No nosso estudo, estas tecnologias funcionam como uma extensão do investigador, na sequências das ideias de McLuhan ${ }^{97}$. A fotografia e o video não são utilizados enquanto método, mas sim como extensão da capacidade do investigador para compreender o espaço urbano. Na construção de uma visão de cima, a fotografia e o video conferem ao investigador a possibilidade de quantificação dos ritmos urbanos que lhe permite compreender os padrões dos ritmos urbanos. Já na construção da visão a partir do terreno, a fotografia e o video funcionam como extensões da capacidade de ser afetado do investigador ${ }^{98}$, permitindo uma terciarização da memória corporal ${ }^{99}$ que auxilia a compreensão dos eventos sensoriais experienciados.

\section{Conclusão}

A metodologia aplicada permitiu-nos compreender os ritmos urbanos no Chiado através de aproximações múltiplas e complementares. Através da combinação de uma visão de cima com uma visão a partir do terreno, foi possível no nosso estudo empírico identificar uma série de padrões espácio-temporais no Chiado e caracterizá-los social e geograficamente, bem como estabelecer uma relação com os ciclos anuais de temperatura e exposição solar. Geramos assim uma compreensão da ecologia entre indivíduos, espaço urbano, e meio ambiente na constituição dos ritmos urbanos. Esta compreensão foi aprofundada através do estudo localizado das performances artísticas e o seu papel interventivo nos ritmos urbanos através da produção de novos estímulos sensoriais. No seu conjunto, este estudo permite não só compreender as dinâmicas rítmicas e sociais de um lugar mas também as potencialidades políticas da intervenção nesse local, destacando o papel dos fluxos sensoriais e afetivos.

Deste modo, emerge um entendimento dos ritmos urbanos que não os reduz a um estado de stasis, nem se limita ao conhecimento situado das percepções desses ritmos, promovendo antes um encontro entre a literatura que se foca na previsibilidade dos padrões rítmicos ${ }^{100}$ e a literatura que aborda a fluidez dos ritmos urbanos $^{101}$. Como Degen ${ }^{102}$ sublinha, os ritmos urbanos são compostos de padrões de actividades e fluxos sensoriais que importa abordar conjuntamente. No entanto, como Edensor ${ }^{103}$ argumenta, ao analisar a performance e as práticas do quotidiano, torna-se difícil visualizar padrões. Pode-se também acrescentar que perspetivas macro regularmente reduzem a vida urbana a mapas estáticos a que Thrift e

97 McLuhan, 1964.

98 Greenhough, 2010; McCormack, 2013.

99 Stiegler, 2010.

100 Pradel, 2010; Marmolejo e Cerda, 2012; Pradel, 2013, Neuhaus, 2015; Marmolejo e Torné, 2015; Mulíček et al., 2015; Mulíček et al. 2016; Kärrholm, 2016.

101 Simpson, 2008; Vergunst, 2010; Vannini, 2012; Lagerkvist, 2013; Goh, 2014; Rodó de Zárate, 2015; Prieto de la Fuente, 2015; Paiva, 2016.

102 Degen, 2010.

103 Edensor, 2010. 
Dewsbury ${ }^{104}$ chamaram de 'geografias mortas'. De facto, uma das questões centrais deste problema prende-se com a escala. Na criação de geoetnografias, mais do que a combinação de duas escalas, importa salientar o potencial desta metodologia para informar abordagens macro com dados micro e vice-versa. Deste modo, como ficou evidente, a geoetnografia funciona melhor num sistema de retroalimentação em que os dados 'a partir da janela' informam a análise dos dados 'a partir do terreno' e vice-versa.

Por outro lado, a geoetnografia dos ritmos urbanos permite contornar limitações recorrentes no estudo da vida urbana. Por um lado, evita-se a falácia do 'truque de deus' ${ }^{105}$, i.e. a ideia de que é possível uma perspetiva única a partir da qual o conhecimento que emerge é universal e neutro. Na geografia, este 'truque de deus' geralmente é feito a partir do mapa onde se espacializam dados quantificados por vezes acriticamente. Por outro lado, as perspetivas micro sobre a vida urbana têm sido criticadas pelo particularismo e indeterminação dos dados ${ }^{106}$, várias vezes difíceis de traduzir para outros contextos urbanos ${ }^{107}$. A geoetnografia dos ritmos urbanos permite uma crítica da produção dos padrões, ao providenciar dados qualitativos de caracterização dos utilizadores, dos movimentos, das práticas e dos recursos utilizados na produção desses padrões, bem como os fluxos sensoriais que deles emergem. Ao mesmo tempo, oferece-nos a possibilidade de contextualizar dados à escala micro, nomeadamente qualitativos, e desse modo identificar e explorar o que há de particular ou significante nos ritmos urbanos, como o caso das performances artísticas no Chiado.

Evitamos aqui cair na tentação de criar uma definição precisa e definitiva de geoetnografia. Na história da geografia, a etnografia tem tido papéis diferenciados, desde a sua utilização na escola regional ${ }^{108}$ até à sua redescoberta recente no âmbito da geografia cultural ${ }^{109}$. A intersecção de métodos geográficos, nomeadamente aqueles ligados à cartografia e aos sistemas de informação geográfica, com métodos etnográficos tem sido realizada com alguma regularidade e em diversas formas, como vimos ${ }^{110}$, pelo que uma definição única e definitiva parece-nos contraproducente. Enquanto ciência aplicada, a geografia precisa necessariamente de adaptar as suas metodologias às realidades que estuda. Não obstante, uma geoetnografía deve-se pautar pela concatenação de uma visão geográfica abrangente, ainda que a uma escala local como a que usamos nosso estudo, que mobiliza conhecimento cartográfico e sistemas de informação geográfica, com uma visão etnográfica assente no terreno, que permita aprofundar o conhecimento sobre determinadas variáveis qualitativas que explicam contextos particulares ou factos gerais. Uma geoetnogra-

104 Thrift e Dewsbury, 2000.

105 Haraway, 1988.

106 Storper e Scott, 2016.

107 McFarlane, 2010; Robinson, 2010.

108 Velasco-Graciet, 2008.

109 Crang e Cook, 2007; Anderson, 2009; Cresswell, 2012.

110 Matthews, Detwiler e Burton, 2005; Biffle e Thompson, 2006; Kwan e Ding, 2008; Souza et al., 2009; Nofre et al. 2015. 
fia é particularmente valiosa quando permite o cruzamento de dados quantitativos e qualitativos mutuamente complementares e uma visualização, ou no mínimo um enquadramento espacial, desses dados.

A proposta que aqui apresentámos é entender a geoetnografia como metodologia para o estudo dos ritmos urbanos. Vista por este prisma, a geoetnografia permite o encontro entre padrões e fluidez, entre atividade e sensação, entre macro e micro, e entre quantitativo e qualitativo. Cremos que a metodologia que aqui apresentamos pode ter utilidade para investigadores em diferentes áreas das ciências sociais que abordam a vida urbana, como a etnografia, a geografia, a antropologia ou a sociologia, e também contribua para sublinhar o valor acrescentado que existe na combinação de métodos de disciplinas diferentes.

\section{Bibliografia}

ABRANTES, Jorge. O Contributo das Companhias Aéreas de Baixo Custo para o Desenvolvimento dos Hostels nas Cidades de Lisboa e Porto. Lisboa: Universidade de Lisboa, 2016.

AELBRECHT, Patricia. 'Fourth places': the contemporary public settings for informal social interaction among strangers. Journal of Urban Design, 2016, vol. 21, no. 1, p. 124-152.

AMIN, Ash. Collective culture and urban public space, City: analysis of urban trends, culture, theory, policy, action, 2008, vol12, no. 1, p. 5-24.

ANDERSON, Ben. Encountering Affect: Capacities, Apparatuses, Conditions, Londres: Ashgate, 2014.

AUGE, Marc. Non-Lieux: Introduction à une anthropologie de la surmodernité. Paris: Editions du Seuil, 1992.

ANDERSON, Jon. Understanding cultural geography: places and traces. New York: Routledge, 2009.

ASH, James e SIMPSON, Paul. Geography and post-phenomenology. Progress in Human Geography. [Online] <http://phg.sagepub.com/content/early/2014/08/07/0309132514544806.abstract> [13 de Outubro de 2016].

BALSAS, Carlos. City Centre Revitalization in Portugal: A Study of Lisbon and Porto, Journal of Urban Design, 2007, vol.12, no. 2, p.231-259.

BARATA-SALGUEIRO, Teresa. Novas formas de comércio. Finisterra: Revista Portuguesa de Geografia, 1989, vol. XXIV, no. 48, p. 151-217.

BARATA-SALGUEIRO, Teresa. Lisboa. Periferia e Centralidades. Oeiras: Celta Editora, 2001.

BIFFLE, Richard e THOMPSON, Pamela. Geo-Ethnography, An Interdisciplinary Method for Exploring Schools, Communities and Cultures: Creating Personal Narratives of Place and Voice. International Journal of Diversity in Organizations, Communities and Nations, 2006, vol. 6, no. 3, p.75-82.

CONNOLLY, W.E. Neuropolitics: Thinking, Culture, Speed. Minneapolis: University of Minnesota Press, 2002. 
CRANG, Mike. Rhythms of the City: Temporalised Space and Motion. In MAY, Jon; THRIFT, Nigel (eds.) Timespace - Geographies of Temporality. Londres: Routledge, 2001, p. 187-207.

CRANG, Mike. Temporal ecologies: multiple times, multiple spaces, and complicating space times, Environment and Planning A, 2012, no 44, p. $2119-2123$.

CRANG, Mike e COOK, Ian. 2007. Doing ethnographies. Londres: Sage, 2007.

CRESSWELL, Tim. Geographic thought: a critical introduction. Londres: Wiley, 2012.

DANIELS, Inge. Feeling at home in contemporary Japan: Space, atmosphere and intimacy. Emotion, Space and Society, 2015, vol. 15, p. 47-55.

de CERTEAU, Michel. The Practice of Everyday Life. Londres: University of California Press, 1984.

DEGEN, Monica. Consuming urban rhythms: let's ravalejar. In EDENSOR, Tim (ed.) Geographies of Rhythm - Nature, Place, Mobilities and Bodies, Surrey: Ashgate, 2010, p. 21-32.

DELEUZE, Gilles. Spinoza: Practical Philosophy. São Francisco: City Lights Books, 1988.

DELEUZE, Gilles e GUATTARI, Felix. A Thousand Plateaus. Capitalism and Schizophrenia. Londres: University of Minnesota Press, 1987.

DEWSBURY, J.D. Non-representational landscapes and the performative affective forces of habit: from 'Live' to 'Blank'. cultural geographies, 2015, vol. 22, no. 1, p. 29-47.

DOUGHTY, K e LAGERQVIST, M. The ethical potential of sound in public space: migrant pan flute music and its potential to create moments of conviviality in a 'failed' public square. Emotion, Space and Society, 2016, 20, p. 58-67.

DUFFY, Michelle; WAITT, Gordon. Sound diaries: a method for listening to place. Aether: The Journal of Media Geography, 201 1, vol. VII, p. 119-136.

EDENSOR, Tim. Geographies of Rhythms. Nature, Place, Mobilities and Bodies. Londres: Ashgate, 2010.

GALLAGHER, Michael. Field recording and the sounding of spaces. Environment and Planning D, 2015, vol. 33, no. 3, p. 560-576.

GALLAGHER, Michael e PRIOR, Jonathan. Sonic geographies. Exploring phonographic methods. Progress in Human Geography, 2014, vol. 38, no. 2, p. 267-284.

GOH, Daniel. Walking the Global City: The Politics of Rhythm and Memory in Singapore. Space and Culture, 2014, vol. 17, no. 1, p. 16-28.

GREENHOUGH, Beth. Vitalist geographies: life and the more-than-human. In ANDERSON, Ben e HARRISON, Paul. (eds.) Taking-place: Non-representational Theories and Geography, Surrey: Ashgate, 2010, p. 37-54.

GRIFFERO, Tonino. Atmospheres: Aesthetics of Emotional Spaces, Londres: Ashgate, 2014.

GREGG, Melissa e SEIGWORTH, Gregory. The Affect Theory Reader. Duke University Press, 2010. 
GUIMARÃES, Pedro. O planeamento comercial em Portugal : os projectos especiais de urbanismo comercial. Lisboa: Universidade de Lisboa, 2015.

HARAWAY, Donna. Situated knowledges: the science question in feminism and the privilege of partial perspective. Feminist Studies, 1988, vol. 14, no. 3, p. 575-599.

HENRY, Michel. Material Phenomenology. Nova Iorque: Fordham University Press, 2008.

HOWES, David. Empire of the senses: The sensual culture reader. Oxford: Berg, 2005. JANEIRO, Maria João. Lisboa: Histórias e Memórias. Lisboa: Livros Horizonte, 2006. KÄRRHOLM, Mattias. To the rhythm of shopping-on synchronisation in urban landscapes of consumption. Social \& Cultural Geography, 2009, vol. 10, no. 4, p. 421-440.

KÄRRHOLM, Mattias. The main square revisited. A comparison of daily usage of Stortoget, Malmö, between 1978 and 2013. In Kärrholm, Mattias (Ed.) Urban Squares. Spatio-temporal studies of design and everyday life in the Öresund region. Lund: Nordic Academic Press, 2015, p. 17-56.

KÄRRHOLM, Mattias. The temporality of territorial production - the case of Stortorget, Malmö. Social and Cultural Geography. [Online] <http://dx.doi.org/10.1080 /14649365.2016.1211313> (13 de Outubro de 2016).

KWAN, Mei-Po e DING, Guoxiang. Geo-Narrative: Extending Geographic Information Systems for Narrative Analysis in Qualitative and Mixed-Method Research. The Professional Geographer, 2008, vol. 60, p. 443-465.

LAGERKVIST, Amanda. Communicating the rhythms of retromodernity: 'confused and mixed Shanghai'. The Sociological Review, 2013, vol. 61, no. S1, p. 144-161

LATHAM, Alan. Research, performance, and doing human geography: some reflections on the diary-photograph, diary-interview method. Environment and Planning A, 2003, vol. 35, no. 11, p. 1993-2017.

LATOUR, Bruno. Reassembling the Social. An introduction to Actor-Network-Theory. Oxford, Oxford University Press, 2005.

LEFEBVRE, Henri. The Production of Space. Londres: Wiley-Blackwell, 1992.

LEFEBVRE, Henri. Rhythmanalysis: Space, Time and Everyday Life. Londres: Continuum, 2004.

LEHTOVUORI, Pani e KOSKELA, Hille. From momentary to historic: rhythms in the social production of urban space, the case of Calçada de Sant'Ana, Lisbon. The Sociological Review, 2013, vol. 61, no. S1, p. 124-143.

McLUHAN, Marshall. Understanding media: the extensions of man. New York: McGraw-Hill, 1964.

MASSEY, Doreen. For Space. Londres, Sage, 2005.

MATTHEWS, Stephen, Detwiler, James e Burton, Linda. Geo-ethnography: coupling geographic information analysis techniques with ethnographic methods in urban research. Cartographica, 2005, vol. 40, no. 4, p. 75-90.

McCORMACK, Derek. Refrains for Moving Bodies: Experience and Experiment in Affective Spaces. Durham, Duke University Press, 2013. 
McFARLANE, Colin. The Comparative City: Knowledge, Learning, Urbanism. International Journal of Urban and Regional Research, 2010 , vol. 34, no. 4, p. 725-742.

MULÍČEK, Ondřej, OSMAN, Robert e SEIDENGLANZ, Daniel. Urban rhythms: A chronotopic approach to urban timespace. Time \& Society, 2015, vol. 24, no. 3, p. 304-325.

MULÍČEK, Ondřej, OSMAN, Robert e SEIDENGLANZ, Daniel. Time-space rhythms of the city-The industrial and postindustrial Brno. Environment and Planning A, 2016, vol. 48, no. 1, p. 115-131.

NEUHAUS, Fabian. Emergent Spatio-Temporal Dimensions of the City. Habitus and Urban Rhythms. Londres: Springer, 2015.

NOFRE, J.; MALET-CALVO, D.; CASSÁN A. e Wodzinska, S. (2016) ‘Club Carib’: A Geo-ethnography of seduction in a dancing bar of Lisbon. Social \& Cultural Geography. [Online] <http://dx.doi.org/10.1080/14649365.2016.124719l> (20 de Outubro de 2016).

PAIVA, Daniel. Collapsed rhythms: the impact of urban change in the everyday life of elders. Space and Culture, vol. 19, no. 4, p. 345-360.

PAIVA, Daniel; CACHINHO, Herculano e BARATA-SALGUEIRO, Teresa. The pace of life and temporal resources in a neighborhood of an edge city. Time \& Society. [Online] < 10.1177/0961463X15596704> (22 de Julho de 2015).

PEET, Richard. Modern Geographical Thought. Londres: Wiley-Blackwell, 1998.

PINK, Sarah. Doing Visual Ethnography. Londres: Sage, 2007.

PINK, Sarah. Doing Sensory Ethnography. Londres: Sage, 2009.

PRADEL, Benjamin. Rendez-vous en ville! Urbanisme temporaire et urbanité événementielle: les nouveaux rhythmes collectifs. Paris: Université Paris-Est, 2010.

PRADEL, Benjamin. Rythmes événementiels et aménagement des espaces publics à Paris, Bruxelles et Montréal. Loisir et Société / Society and Leisure, 2013, vol. 36, no. 1, p. 78-93.

PRIETO de la FUENTE, Paulina. Discrete architectures. Rhythms of public eating in Värnhemstorget in Malmö. In KÄRRHOLM, Mattias (ed.) Urban Squares. Spatio-temporal studies of design and everyday life in the Öresund region. Lund: Nordic Academic Press, 2015, p. 57-86.

RANCIÈRE, Jacques. The Politics of Aesthetics: The Distribution of the Sensible. Londres: Continuum, 2004.

RIO FERNANDES, José e CHAMUSCA, Pedro. Dinâmicas recentes e urbanismo na área central do Porto. Morte, resistência, resiliência e elitização no centro histórico e na Baixa. In RIO FERNANDES, José e SPOSITO, Maria (ed.) A nova vida do velho centro nas cidades portuguesas e brasileiras. Porto: CEGOT, 2013, p. 83-96. ROBINSON, Jennifer. Cities in a World of Cities: The Comparative Gesture. International Journal of Urban and Regional Research, 2011 , vol. 35, no. 1, p. 1-23.

ROSE, Gillian. Visual Methodologies. Londres: Sage, 2007.

SEAMON, David. A Geography of the Lifeworld: Movement, Rest and Encounter. Londres: Croom Helm, 1979. 
SIMPSON, Paul. Chronic everyday life: rhythmanalysing street performance. Social \& Cultural Geography, 2008, vol. 9, no. 7, p. 807-829.

SIMPSON, Paul. Apprehending everyday rhythms: rhythmanalysis, time-lapse photography, and the space-times of street performance. Cultural geographies, 2012, vol. 19, no. 4, p. 423-445.

SIMPSON, Paul. Sonic affects and the production of space: 'music by handle' and the politics of street music in Victorian London. cultural geographies. [Online] $<10.1177 / 1474474016649400>$ [25 de Maio de 2016].

SOUZA, Angela; MARTINS, Geraldo; dos SANTOS, Rodrigo e BRANDÃO, Carlos. A Geo-etnografia da Barra do Pacuí: experiências vividas nos lugares, nos espaços e entre a gente do sertão. Revista Unimontes Científica, 2009, vol. 12, no. 1/2, p. 37-45.

SPINNEY, Justin. Close encounters? Mobile methods, (post)phenomenology and affect. cultural geographies, 2015, vol. 22, no. 2, p. 231-246.

STEWART, Kathleen. Atmospheric Attunements. Environment and Planning D: Society and Space, 2011 , vol. 29, no. 3, p. 445-453.

STIEGLER, Bernard. For a new critique of political economy. Cambridge: Polity Press, 2010.

STOLLER, Paul. The Taste of Ethnographic Things. The Senses in Anthropology. Philadelphia: University of Pennsylvania Press, 1989.

STOLLER, Paul. Sensuous Scholarship. Philadelphia: University of Pennsylvania Press, 1997.

STORPER, Michael e SCOTT, Allen. Current debates in urban theory: A critical assessment. Urban Studies. 2016, vol. 53, no. 6, p. $1114-1136$.

THRIFT, Nigel. Non-representational Theory. Space, Politics, Affect. Oxon: Routledge, 2008.

THRIFT, Nigel. Lifeworld Inc-and what to do about it. Environment and Planning D: Society and Space, 201 1, vol. 29, no. 1, p. 5-26.

THRIFT, Nigel e DEWSBURY, J.D. Dead geographies-and how to make them live. Environment and Planning D: Society and Space, 2000, vol. 18, no. 4, p. 411-432.

Tiwari, Reena. Being a Rhythm Analyst in the City of Varanasi. Urban Forum, 2008, vol. 19, no. 3, p. 289-306.

URRY, John e LARSEN, Jonas. The Tourist Gaze 3.0. Londres: Sage, 2012.

VANNINI, Phillip; WASKUL, Dennis e GOTTSCHALK, Simon. The Senses in Self, Society, and Culture: A Sociology of the Senses. Londres: Routledge, 2011.

VANNINI, Phillip. In Time, Out of Time: Rhythmanalyzing Ferry Mobilities. Time \& Society, 2012, vol. 21, no. 2, p. 241-269.

VANNINI, Phillip. Non-Representational Methodologies: Re-Envisioning Research. New York, Routledge, 2015a.

VANNINI, Phillip. Non-representational ethnography: new ways of animating lifeworlds. cultural geographies, 2015b, vol. 22, no. 2, p. 317-327. 
VELASCO-GRACIET, Hélène. Retour sur le terrain. La question du terrain tropical en géographie. In Hélène VELASCO-GRACIET (ed.) Les tropiques des géographers. Pessac: Maison des Sciences de l'Homme d'Aquitaine, 2008, p. 125-143.

VERGUNST, Jon. Rhythms of Walking: History and Presence in a City Street. Space and Culture, 2010, vol. 13, p. 376-387.

VROBEL, Susie. Measuring the Temporal Extension of the Now. Progress in Biophysics and Molecular Biology, 2013, vol. 113, p. 92-96.

WUNDERLICH, Filipa. Walking and Rhythmicity: Sensing Urban Space. Journal of Urban Design, 2008, vol. 13, no. 1, p. 125-139.

WUNDERLICH, Filipa. Place-Temporality and Urban Place-Rhythms in Urban Analysis and Design: An Aesthetic Akin to Music. Journal of Urban Design, 2013, vol. 18, no. 3, p. 383-408.

ZERUBAVEL, Eviatar. Hidden Rhythms: Schedules and Calendars in Social Life. Los Angeles: University of California Press, 1985.

(C) Copyright: Daniel Paiva, 2017

(c) Copyright: Herculano Cachinho, 2017

(c) Copyright: Teresa Barata-Salgueiro, 2017

(c) Copyright: Anselmo Amílcar, 2017

(c) Copyright Scripta Nova, 2017.

Ficha bibliográfica:

PAIVA, Daniel; CACHINHO, Herculano; BARATA-SALGUEIRO, Teresa; AMÍLCAR, Anselmo. A criação de geoetnografias como metodologia para o estudo dos ritmos urbanos. Uma aplicação no Chiado, Lisboa. Scripta Nova. Revista Electrónica de Geografía y Ciencias Sociales. Barcelona: Universidad de Barcelona, 30 de junio de 2017, vol. XXI, no 569. [ISSN: 1138-9788]. 